\title{
Intratumoral immunotherapy with TLR7/8 agonist MEDI9197 modulates the tumor microenvironment leading to enhanced activity when combined with other immunotherapies
}

\author{
Stefanie R. Mullins ${ }^{1 *}$ (D) John P. Vasilakos ${ }^{2}$, Katharina Deschler ${ }^{1}$, Iwen Grigsby ${ }^{2}$, Pete Gillis², Julius John²,
} Matthew J. Elder ${ }^{1}$, John Swales ${ }^{4}$, Elina Timosenko ${ }^{1}$, Zachary Cooper ${ }^{3}$, Simon J. Dovedi ${ }^{1}$, Andrew J. Leishman ${ }^{1}$, Nadia Luheshi', James Elvecrog ${ }^{2}$, Ashenafi Tilahun ${ }^{2}$, Richard Goodwin ${ }^{4}$, Ronald Herbst ${ }^{3}$, Mark A. Tomai ${ }^{2}$ and Robert W. Wilkinson ${ }^{1 *}$

\begin{abstract}
Background: Immune checkpoint blockade (ICB) promotes adaptive immunity and tumor regression in some cancer patients. However, in patients with immunologically "cold" tumors, tumor-resident innate immune cell activation may be required to prime an adaptive immune response and so exploit the full potential of ICB. Whilst Toll-like receptor (TLR) agonists have been used topically to successfully treat some superficial skin tumors, systemic TLR agonists have not been well-tolerated.

Methods: The response of human immune cells to TLR7 and 8 agonism was measured in primary human immune cell assays. MEDI9197 (3M-052) was designed as a novel lipophilic TLR7/8 agonist that is retained at the injection site, limiting systemic exposure. Retention of the TLR7/8 agonist at the site of injection was demonstrated using quantitative whole-body autoradiography, HPLC-UV, and MALDI mass spectrometry imaging. Pharmacodynamic changes on T cells from TLR7/8 agonist treated B16-OVA tumors was assessed by histology, quantitative real time $P C R$, and flow cytometry. Combination activity of TLR7/8 agonism with immunotherapies was assessed in vitro by human DC-T cell MLR assay, and in vivo using multiple syngeneic mouse tumor models.

Results: Targeting both TLR7 and 8 triggers an innate and adaptive immune response in primary human immune cells, exemplified by secretion of IFNa, IL-12 and IFNy. In contrast, a STING or a TLR9 agonist primarily induces release of IFNa. We demonstrate that the TLR7/8 agonist, MEDI9197, is retained at the sight of injection with limited systemic exposure. This localized TLR7/8 agonism leads to Th1 polarization, enrichment and activation of natural killer (NK) and $\mathrm{CD}^{+} \mathrm{T}$ cells, and inhibition of tumor growth in multiple syngeneic models. The anti-tumor activity of this TLR7/8 agonist is enhanced when combined with T cell-targeted immunotherapies in pre-clinical models.

Conclusion: Localized TLR7/8 agonism can enhance recruitment and activation of immune cells in tumors and polarize anti-tumor immunity towards a Th1 response. Moreover, we demonstrate that the anti-tumor effects of this TLR7/8 agonist can be enhanced through combination with checkpoint inhibitors and co-stimulatory agonists.
\end{abstract}

Keywords: TLR, Immunotherapy, Immune checkpoint blockade, T cell agonist, T cell

\footnotetext{
* Correspondence: stefanie.mullins@astrazeneca.com;

wilkinsonr@medimmune.com

${ }^{1} R \& D$ Oncology, AstraZeneca Ltd, Aaron Klug Building, Granta Park,

Cambridge CB21 6GH, UK

Full list of author information is available at the end of the article
}

(c) The Author(s). 2019 Open Access This article is distributed under the terms of the Creative Commons Attribution 4.0 International License (http://creativecommons.org/licenses/by/4.0/), which permits unrestricted use, distribution, and reproduction in any medium, provided you give appropriate credit to the original author(s) and the source, provide a link to the Creative Commons license, and indicate if changes were made. The Creative Commons Public Domain Dedication waiver (http://creativecommons.org/publicdomain/zero/1.0/) applies to the data made available in this article, unless otherwise stated. 


\section{Introduction}

ICB monoclonal antibodies (mAbs) targeting inhibitory pathways at the $\mathrm{T}$ cell synapse to modulate $\mathrm{T}$ cell function have shown activity in the treatment of multiple cancers, as demonstrated by numerous regulatory approvals $[1,2]$. However, monotherapy response rates to ICB mAbs remain low, and additional therapies are required. Clinical response to ICB mAbs correlates with the presence of high densities of tumor infiltrating $\mathrm{CD} 8^{+}$ T cells (TILs, a so called "hot" tumor microenvironment) [3]. Patients with few TILs, so called "cold" tumors, tend to respond poorly to ICB mAbs. Therapeutic strategies that target tumor-resident innate immune cells and induce local tumor proinflammatory responses, which recruit $\mathrm{CD}^{+}$TILs, may be required to fully exploit the potential of ICB mAbs.

One strategy to turn an immunologically cold tumor hot is to promote activation of antigen presenting cells (APC) by targeting the endosomal TLRs TLR3, TLR7, TLR8, TLR9, or by targeting the ER-associated signalling molecule stimulator of interferon genes (STING). TLR3, TLR7, TLR8, and TLR9 recognise single and double stranded viral RNA and bacterial CPG DNA in the endosome following internalisation by APCs. STING senses aberrant DNA species or cyclic dinucleotides in the cytosol [4]. TLR and STING signalling activates APCs, increasing expression of inflammatory cytokines and co-stimulatory molecules, and enhancing antigen presentation capacity. Thus, APC activation by TLRs or STING can promote switching of $\mathrm{CD}^{+} \mathrm{T}$ cell response from Th2 to Th1, enhance $\mathrm{CD} 8^{+} \mathrm{T}$ cell responses, and inhibit $\mathrm{T}$ regulatory cell responses [5-9].

TLR7/8 agonists (imidazoquinolines), TLR9 agonists (synthetic CpG oligonucleotides) and STING agonists (cyclic di-nucleotides) have all shown potent antitumor activity in a range of murine cancer models [4]. The clinical utility of systemically delivered TLR agonists has been limited due to toxicity $[10,11]$. In contrast, direct dermal application of Imiquimod (TLR7 agonist) or Resiquimod (TLR7/8 agonist) promotes local immune activation while limiting systemic exposure and side-effects and has clinical activity in treating multiple cutaneous tumor types [12]. Imiquimod is also approved as a topical treatment for external genital warts, actinic keratosis, and superficial basal cell carcinoma (Aldara approved product labelling; [12-16]). However, the utility of these topical treatments is confined to patients with cutaneous lesions.

Intratumoral (IT) TLR or STING agonist therapy has the potential to treat patients with solid tumors. The potential of IT therapeutic anti-cancer agents in the clinic is underscored by the recent approval of the oncolytic viral product T-VEC $[17,18]$. In preclinical models, TLR and STING agonists delivered IT have promising antitumor activity $[4,19]$.
A TLR7/8 agonist has the potential to activate a broader range of human APCs versus targeting TLR9 within the tumor microenvironment, since TLR7 and TLR9 are both expressed on plasmacytoid dendritic cells (pDCs) and $\mathrm{B}$ cells, whereas TLR8 is more widely expressed on monocytes and myeloid dendritic cells (mDCs) [20]. Furthermore, it was hypothesized that retention of the TLR7/8 agonist in the tumor may be important for efficacy. Since the TLR7/8 agonist Resiquimod is known to distribute quickly into the systemic circulation after injection [21], MEDI9197, a dual TLR 7/8 agonist, was designed with a lipid tail to reduce aqueous solubility leading to retention at the injection site, rather than rapidly distributing throughout the body. MEDI9197 has been shown to have activity in mouse vaccine and cancer models and synergize with other immunotherapies [22-24].

In this manuscript we demonstrate that targeting TLR7 and 8 compared with TLR9 or STING in human PBMCs leads to induction of a broader range of cytokines. In murine syngeneic tumor models, MEDI9197 modulates the tumor microenvironment (TME) to an inflamed immunophenotype and increases the anti-tumor efficacy of immune co-stimulatory molecule agonists.

\section{Materials and methods \\ TLR reporter assay}

Human TLR7, human TLR8, or mouse TLR7 HEK293 reporter cells (InvivoGen) were seeded at $3 \times 10^{4}$ cells/ 96-well for $24 \mathrm{~h}$ then treated with MEDI9197 or DMSO for $24 \mathrm{~h}$. Secreted alkaline phosphatase (SEAP) was measured from supernatants using QuantiBlue reagent (InvivoGen).

\section{DC activation and cytokine production}

$\mathrm{pDC}$ and $\mathrm{mDC}$ were enriched from PBMCs by magnetic bead negative selection (Miltenyi Biotec). Cells were resuspended at $4 \times 10^{5}$ cells $/ \mathrm{mL}$ in serum-free AIM V medium and cultured for $24 \mathrm{~h}$ in 96-well plates with MEDI9197 or DMSO. Supernatants were analysed for IFN $\alpha$ and IL-12p40 by ELISA (Mabtech and Affymetrix eBioscience, respectively).

\section{IL-12 release in human macrophages}

$\mathrm{CD}_{1} 4^{+}$cells were purified from PBMCs using the EasySep ${ }^{\mathrm{mm}}$ Human Monocyte Enrichment Kit (StemCell Technologies) and differentiated into macrophages with $100 \mathrm{ng} / \mathrm{mL}$ recombinant human M-CSF (Peprotech). After 6 days cells were harvested, seeded in 96 well plates and rested overnight. Cells were primed with $20 \mathrm{ng} / \mathrm{mL}$ human recombinant IFNY (R\&D systems) for $24 \mathrm{~h}$, followed by $3 \mu \mathrm{M}$ MEDI9197 or $20 \mathrm{ng} / \mathrm{mL}$ LPS (Invivogen) for $24 \mathrm{~h}$. Supernatants were analysed for IL-12p70 using the human IL12p70 ELISA Duoset kit (R\&D). 
PBMC activation, cytokine and FACS analysis

$3-5 \times 10^{5}$ PBMCs were seeded in 96-well plates and stimulated with MEDI9197 (in DMSO), CpG (ODN 2395 VacciGrade $^{\text {Tx }}$ in $\mathrm{H}_{2} \mathrm{O}$, Invivogen), STING agonist (2'3'-c-diAM (PS)2 (Rp,Rp) VacciGrade ${ }^{\mathrm{m}}$ in $\mathrm{H}_{2} \mathrm{O}$, Invivogen), Resiquimod (in DMSO, Sigma-Aldrich), or Imiquimod (in DMSO, R\&D Systems) at the indicated concentrations for $24 \mathrm{~h}$ at $37^{\circ} \mathrm{C}$. Flow cytometry was performed by standard procedures with intracellular fixation buffer from eBioscience. See Additional file 1 for a list of Flow cytometry antibodies. IFN-gamma was analysed by ELISA (Standard: human recombinant IFN $\gamma(\mathrm{R} \& \mathrm{D})$. Capture antibody: Anti-human IFNY (Clone NIB42, Pharmingen). Detection antibody: Biotinylated anti-human IFNY (Clone 4S.B3, Pharmingen) or MSD (Mesoscale Diagnostics). IFN-alpha was analysed by ELISA (MABTECH) and IL-12p70 by MSD (Mesoscale Diagnostics). For ELISAs, DELFIA readout (Perkin Elmer) was used.

\section{PHA-induced cytokine assay}

$2 \times 10^{5}$ human PBMCs were seeded in 96-well plates and treated with MEDI9197 or DMSO for $2.5 \mathrm{~h}$, then incubated with $10 \mu \mathrm{g} / \mathrm{mL}$ PHA-L (Roche) for $45.5 \mathrm{~h}$ at $37^{\circ} \mathrm{C}$. IL-5 was assessed in supernatants using human IL-5 ELISA Set (BD OptEIA,) with DELFIA readout (Perkin Elmer).

\section{Natural killer (NK) cell killing assay}

$2 \times 10^{6}$ cells $/ \mathrm{mL}$ human PBMCs were cultured for $24 \mathrm{~h}$ at $37^{\circ} \mathrm{C}$ with $3 \mu \mathrm{M}$ MEDI9197 or DMSO. NK cells were then isolated using an EasySep ${ }^{\circ}$ Human NK Cell Enrichment Kit (Stemcell). K562 target cells (ECACC,) were loaded for 20 min with DELFIA BATDA reagent (Perkin Elmer) at $37^{\circ} \mathrm{C}$, washed 5 times in PBS, 0.1\% (v/v) BSA, $2.5 \mathrm{mM}$ probenecid (ThermoFisher Scientific) and co-cultured with NK cells for $3 \mathrm{~h}$ at $37^{\circ} \mathrm{C}$ in the presence of $2.5 \mathrm{mM}$ probenecid. Killing was assessed in supernatants by DELFIA EuTDA readout (Perkin Elmer). Percent specific killing was calculated from the fluorescence values of ((Sample - (Target cells only - medium) - (NK cells only - medium) medium $) \times 100) /(100 \%$ lysis - medium $)$.

\section{Peptide-specific recall assay}

$2.5 \times 10^{5} / 96$-well of human PBMCs from donors prescreened for reactivity against CMV peptide NLVPMVATV. were stimulated with $3 \mu \mathrm{M}$ MEDI9197 or DMSO and a titration of CMV peptide. After 5 days, cells were stained for flow cytometry analysis. A list of antibodies and details of flow cytometry can be found in Additional file 1 section.

\section{Mice and rats}

Female C57BL/6 J, BALB/cAnNCrl, C57BL/6 J-TyrC-2 J (C57BL/6 J Albino, Strain B6(Cg)-TyrC-2 J/J), CD-1 ${ }^{\circ}$ IGS mice (Crl:CD1(ICR)) (Charles River or Jackson
Laboratories) at 6-10 weeks of age $(\sim 18-25 \mathrm{~g})$ were used for in vivo studies. Male Sprague Dawley rats (Crl:CD (SD)), 200-400 g, were obtained from Charles River Laboratories.

\section{In vivo studies}

The melanoma cell line B16-OVA was obtained from Dr. Wynette Dietz, University of Minnesota. Cell suspensions were implanted subcutaneously: $5 \times 10^{5}$ B16-OVA cells, $5 \times 10^{3}$ B16-F10 AP3 CAG luc2 (AstraZeneca) cells in 1:1 Matrigel (Corning)/PBS, or B16-F10 AP3, 4 T1 and MC38 cells as previously described [25].

Tumor volume $=\left(\right.$ Length $\left.\times \mathrm{Width}^{2}\right) / 2=\mathrm{mm}^{3}$. Mice were euthanized when tumors reached an average diameter of $15 \mathrm{~mm}$ (or $20 \mathrm{~mm}$ for B16-OVA tumors). Survival was defined as survival to a humane endpoint, based on tumor volume or average diameter and overall condition of the animal.

MEDI9197 and Resiquimod were prepared in sesame oil with $7.5 \% \mathrm{EtOH}(\mathrm{w} / \mathrm{w})$ and citrate buffer, respectively. The $\mathrm{O} / \mathrm{W}$ formulations consisted of $74 \%(\mathrm{v} / \mathrm{v}) 10$ $\mathrm{mM}$ NaCitrate, 20\% (v/v) Soybean Oil, 3\% (v/v) Tween 80 , and $3 \%(\mathrm{v} / \mathrm{v})$ Span 85 with or without $0.04 \%(\mathrm{w} / \mathrm{w})$ MEDI9197 or Resiquimod.

MEDI9197, Resiquimod, or Vehicle solution were administered via IT or subcutaneous (SC) injection. Anti-mouse PD-L1: clone 80 mIgG1 D265A (AstraZeneca), anti-rat PD-L1: clone 10F.9G2 (BioXcell), Mouse GITRL fusion protein [26], anti-mouse OX40: Clone OX86 mIgG $_{2 a}$ (AstraZeneca), anti-mouse NK1.1: clone PK136 mIgG $_{2 \mathrm{a}}$ (BioXcell) or corresponding isotype controls (NIP, AstraZeneca) were injected via intraperitoneal (IP) injection.

For TIL analysis (gene expression or flow cytometry) tumors collected from 6 days after MEDI9197 treatment were enriched for responders. Responders are defined as tumors with drug-induced tumor growth inhibition (average tumor volume $<600 \mathrm{~mm}^{3}$ ). 50\% of MEDI9197 treated tumors were considered responders and groups were powered for this.

\section{Quantitation of $\left[{ }^{14} \mathrm{C}\right]-M E D I 9197$ in rat tissues, whole blood, and plasma}

$\left[{ }^{14} \mathrm{C}\right]$-MEDI9197 was quantified in rat tissues, wholeblood, and plasma by Quotient Bioresearch Ltd., UK after SC injection. Whole-blood and plasma samples were collected via a tail vein or via cardiac puncture. Plasma samples were taken for direct Quantitative Radiochemical analysis (QRA). Whole-blood samples were taken for oxidation prior to QRA.

Distribution of radioactivity in tissues was determined by quantitative whole-body autoradiography (QWBA). Tissue concentrations of radioactivity were determined using calibrated autoradiographic microscales (GE Healthcare). For 
calculation of the weight equivalent/g data, the $\mathrm{nCi} / \mathrm{g}$ data was divided by the relevant specific activity $(84.5 \mu \mathrm{Ci} / \mathrm{mg})$.

\section{TNFa quantitation from rat serum}

TNF $\alpha$ was measured in undiluted serum using Invitrogen's antibody bead kits, according the manufacturer's instructions. The LLQ for TNF $\alpha$ is $2 \mathrm{pg} / \mathrm{mL}$.

\section{MALDI mass spectrometry imaging}

MALDI-MSI experiments were carried out in positive reflectron mode over a mass range of $\mathrm{m} / \mathrm{z} 200$ to 1000 using a MALDI rapifleX tissuetyper (Bruker Daltonics) equipped with a $10 \mathrm{kHz}$ Smartbeam $3 \mathrm{D}^{\mathrm{mm}} \mathrm{Nd}$ :YAG laser. Data collected on the rapifleX was at a spatial resolution of $50 \mu \mathrm{m}$, summing up 500 laser shots/raster position.

FlexImaging 5.0 (Bruker Daltonics) software was used for initial data analysis. Normalization, molecular image extraction and spectral clustering were defined in SCiLS Lab 2018b (Bruker Daltronics) software typically using mass selection window of $\pm 0.05 \mathrm{Da}$. MEDI9197 and heme were detected at $m / z 594.4$ and 616.1, respectively.

\section{MEDI9197 quantitation from tumors and serum}

MEDI9197 quantitation was performed as previously described [27].

\section{Optical imaging of tumor burden}

Mice implanted with B16-F10 CAG luc2 were administered Xenolight D-Luciferin $\mathrm{K}^{+}$salt bioluminescent substrate (IP, $100 \mu \mathrm{L}$ of $33 \mathrm{mg} / \mathrm{mL}$, PerkinElmer). $15 \mathrm{~min}$ after substrate injection, mice were imaged on an IVIS100 under isoflurane at an exposure time of $1 \mathrm{~s}$ using an open filter and field of view C. Image analysis was completed using living Image Software (PerkinElmer). Regions of interest were drawn around the tumors and total counts were generated within the region of interest.

\section{Tumor histology}

Excised tumors were immersed in $10 \%$ buffered formalin and sent to Marshfield Lab, Marshfield, WI for paraffin embedding, sectioning, H\&E staining, and histopathology evaluation. Digital photomicrographs were taken from all sections, and the number of lymphoid aggregates per section were quantified by microscopy (Veterinary Pathologist, Marshfield Lab).

\section{Tumor immune profiling by flow cytometry}

Single cell suspensions from individual tumors were obtained using the murine tumor dissociation kit and a gentleMACS dissociator (Miltenyi Biotec). T and NK cells were stained with viability Zombie Aqua Dye (BioLegend) and fixed in $1 \%$ of paraformaldehyde at $4{ }^{\circ} \mathrm{C}$ for $30 \mathrm{~min}$ prior to FACS analysis.
For in vitro activation of TILs and measurement of intracellular cytokine producing $\mathrm{T}$ cells, leukocytes were enriched using anti-mouse CD45 MicroBeads and collected on LC columns using a MACS separator (Miltenyi Biotec). TILs were collected and resuspended in $1 \mathrm{~mL}$ TexMACSmedium (Miltenyi Biotec) containing cell stimulation cocktail plus protein transport inhibitors (eBioscience/ ThermoFisher Scientific) for $16 \mathrm{~h}$. Activated TILs were evaluated in staining buffer containing protein transport inhibitor cocktails (eBioscience/ThermoFisher Scientific) until the permeabilization/fixation step. A list of all FACS antibodies can be found in the Additional file 1 section.

\section{Measurement of gene expression in mouse tumors}

Tumors were stored in RNAlater ${ }^{\circ}$ RNA stabilization solution at $-20^{\circ} \mathrm{C}$ (Life Technologies) then homogenized in RLT buffer using Miltenyi M tube with a gentleMACS dissociator. Total RNA was isolated using RNeasy Mini Kit according to the manufacturer's protocol. gDNA was removed using RNase-free DNase I (Qiagen).

cDNA was generated using RT2 First Strand Kit (Qiagen). qPCR assays were carried out either using RT2 Profiler PCR Array (Qiagen, Cat. no. 330171 CLAM24673) or PrimeTime qPCR assays (Integrated DNA Technologies). Probe lists can be found in the Additional file 1 section. All qPCR assays were performed with a LightCycler 96 (Roche) using cycling conditions provided by assay manufacturer.

Relative expression levels were quantified using $\Delta \mathrm{Ct}$ (GusB Ct - Target gene Ct).

Fold-Change $=2^{-\Delta \mathrm{Ct}(\text { Treated })} \div 2^{-\Delta \mathrm{Ct}(\text { Control })}=$ Relative quantitation of treated (MEDI9197) $\div$ Relative quantitation of Untreated (Vehicle).

\section{Measurement of tumor specific T cells by ELISpot}

Tumors were excised at days 3,7 , and 11 post-dose (IT$20 \mu \mathrm{g}$ MEDI9197 or IT-Vehicle). TILs were isolated from tumors as described above (Tumor immune profiling section). Lymphocytes from 1 to 3 animals were pooled and 20,000-100,000 lymphocytes per well were analyzed for IFNY and Granzyme B expression using a dual color ELISpot assay (R\&D Systems) following manufacturer's protocol. Lymphocytes were stimulated in duplicate for $24 \mathrm{~h}$ in $200 \mu \mathrm{L}$ AIM-V with PMA/Ionomycin following manufacturer's instructions (BioLegend) or $5 \mu \mathrm{g} / \mathrm{mL}$ of a known H-2K ${ }^{\mathrm{b}}$ [OVA (257-264):SIINFEKL, p53(232-240): CNSSCMGGM, TRP-2(181-188):SVYDFFVWL, MAGEA5 [5-12]:HNTQYCNL, Sendai virus nucleoprotein (324-334) FAPGNYPAL] or $\mathrm{H}-2 \mathrm{D}^{\mathrm{b}}$ [gp100 [25-33]: EGSRNQDWL and Influenza A nucleoprotein (366-374): ASNENMETM] peptide epitopes. SIINFEKL peptide was from InvivoGen all other peptides were from Genscript. All peptides were dissolved at $1 \mathrm{mg} / \mathrm{mL}$ in DMSO. ELISpot assay was performed following manufacturer's instructions. Spots were counted using a CTL ImmunoSpot 
S6 Micro using ImmunoSpot 7.0 ProDC suite (CTL Analyzers, LLC).

\section{Human DC-T cell MLR primary cell assay}

Human Mo-DCs were generated by differentiation of $\mathrm{CD}^{+}{ }^{+}$monocytes (EasySep Human CD14+ positive selection kit (Stemcell)) in the presence of $100 \mathrm{ng} / \mathrm{ml} \mathrm{GM-}$ CSF and $100 \mathrm{ng} / \mathrm{mL}$ IL-4 for 6 days in X-Vivo15 with $2 \%$ human AB serum. Mo-DCs were harvested, seeded, and stimulated with MEDI9197 for $18 \mathrm{~h}$. Allogeneic human $\mathrm{CD}^{+} \mathrm{T}$ cells were isolated using the Human $\mathrm{T}$ cell enrichment kit (Stemcell), then added to the mo-DCs at a ratio of 10:1 and co-cultured for 3-5 days. IL-2 was measured by DELFIA ELISA (R\&D) in day 3 supernatants and IFNY $(\mathrm{BD})$ in day 5 supernatants.

\section{Results}

MEDI9197 activates human innate and adaptive immune cells

MEDI9197 is a dual agonist for TLR7 and TLR8, as confirmed using HEK reporter cells transfected with human TLR7 or human TLR8 (Fig. 1a). Like other imidazoquinolines, MEDI9197 also activates murine TLR7, induces IFN $\gamma$ from mouse splenocytes and has no negative impact on cell viability (Additional file 1: Figure S1A-C). Imidazoquinolines do not agonise murine TLR8, which may account for lower potency in mouse splenocytes compared with human PBMCs.

Given the broad expression of TLR7 and 8 on myeloid subsets [28] we investigated the impact of MEDI9197 on human myeloid cells. MEDI9197 induced IFN $\alpha$ and IL$12 \mathrm{p} 40$ release from $\mathrm{pDC}$ and $\mathrm{mDC}$ populations, respectively, which were enriched from human PBMCs (Fig. 1b). The ability of MEDI9197 to activate human DC populations was further demonstrated by increased IL-12p70 production from Monocyte-derived DCs (Mo-DC) (Additional file 1: Figure S1D). In human IFN $\gamma$-primed primary macrophages MEDI9197 induced IL-12p70 to significantly higher levels than a high dose of LPS ( $\mathrm{p}=0.0075$; average of $33 \mathrm{vs}$. $14 \mathrm{ng} / \mathrm{ml}$ of IL-12 for MEDI9197 and LPS, respectively; Fig. 1c). This shift in macrophage polarization is further evidenced by upregulation of CD40, CD80, IL12A and CD274 (PD-L1) gene expression (Additional file 1: Figure S1E).

We next investigated the ability of MEDI9197 to stimulate innate and adaptive immune cells in human PBMC cultures. MEDI9197 induced the up-regulation of activation markers/co-stimulatory molecules from various human PBMC immune cell populations in vitro (Fig. 1d). These include: CD25 on NK and B cells; $\mathrm{CD} 40$ on $\mathrm{B}$ cells, and $\mathrm{CD} 80$ on pDCs, $\mathrm{CD} 14^{+} \mathrm{CD} 16^{-}$ monocytes, and $\mathrm{CD} 14^{+} \mathrm{CD} 16^{+}$monocytes. Additionally, MEDI9197 skewed polyclonal immune responses away from a Th2-like phenotype by inhibiting IL-5 release from human PBMCs stimulated with PHA (Fig. 1e).
When compared to a C-class CpG (ODN2395) or a STING agonist (2'3'-c-di-AM (PS)2) only MEDI9197 induced high levels of the Th1 cytokines, IFN $\gamma$ and IL12 p70 from PBMC. The hook effect at high concentrations, which has been observed with other TLR7 agonists, is likely the result of differences in the rate of cytokine production [29] and is not due to cytotoxicity ([28], Additional file 1: Figure S1A). MEDI9197 also induced significantly greater IFN $\alpha$ production compared to treatment with the STING agonist and was more potent than C-class CpG. ( $p=0.0013$; Fig. 1f).

In addition to activating APCs, MEDI9197 enhanced the killing capacity of effector cells such as NK and T cells. Priming human PBMCs with MEDI9197 significantly increased target cell killing of K652 leukemia cells by isolated NK cells more than 2-fold at 10:1, 5:1 and even 2:1 NK:target cell ratio $(\mathrm{p}=0.0001, \mathrm{p}=$ $0.0013, \mathrm{p}=0.0185$, respectively; Fig. $1 \mathrm{~g}$ ). In the context of CMV-specific PBMCs, priming with MEDI9197 and CMV-peptide led to an expansion of peptide-specific $\mathrm{CD} 8^{+} \mathrm{T}$ cells (Fig. 1h) with increased effector function (Granzyme B, Fig. 1i). Taken together these in vitro results show that MEDI9197 effectively stimulates the activation and function of innate and adaptive human immune cells.

\section{MEDI9197 is retained at the site of injection and induces} pharmacodynamic responses

The MEDI9197 lipid tail and formulation (sesame oil with $7.5 \%$ ethanol) have been designed to aid local retention of the TLR7/8 agonist at the site of injection to minimize systemic exposure and side effects, such as cytokine release syndrome (CRS). SC administration of radiolabelled MEDI9197 in rats revealed that MEDI9197 was retained at the site of injection for at least 28 days post dosing (Fig. 2a and b). Radiolabelled MEDI9197 was detectable in plasma and whole blood for at least 14 days (Fig. 2c). However, peak levels of MEDI9197 measured by LC-MS/MS in the serum from rats dosed $\mathrm{SC}$ or intramuscularly (IM) remained below $3 \mathrm{ng} / \mathrm{mL}$ (Additional file 1: Figure S2A, B). This is 20 times lower than the minimum effective concentration (MEC) of $59 \mathrm{ng} / \mathrm{mL}$ for MEDI9197 to induce cytokines from human PBMCs in vitro (data not shown). Low systemic exposure and subsequent pharmacodynamic (PD) effects of MEDI9197 were examined further in a separate rat study. MEDI9197 induced very low levels of systemic serum TNF $\alpha$ levels (peaking at $16 \mathrm{pg} / \mathrm{mL} 18 \mathrm{~h}$ post-dose) compared with Resiquimod (1212 pg/mL $2 \mathrm{~h}$ post-dose) after SC dosing (Fig. 2d).

MEDI9197 retention at the site of injection was qualitatively observed in the B16-F10 AP3 mouse melanoma model following administration of $20 \mu \mathrm{g}$ MEDI9197 injected IT, by 


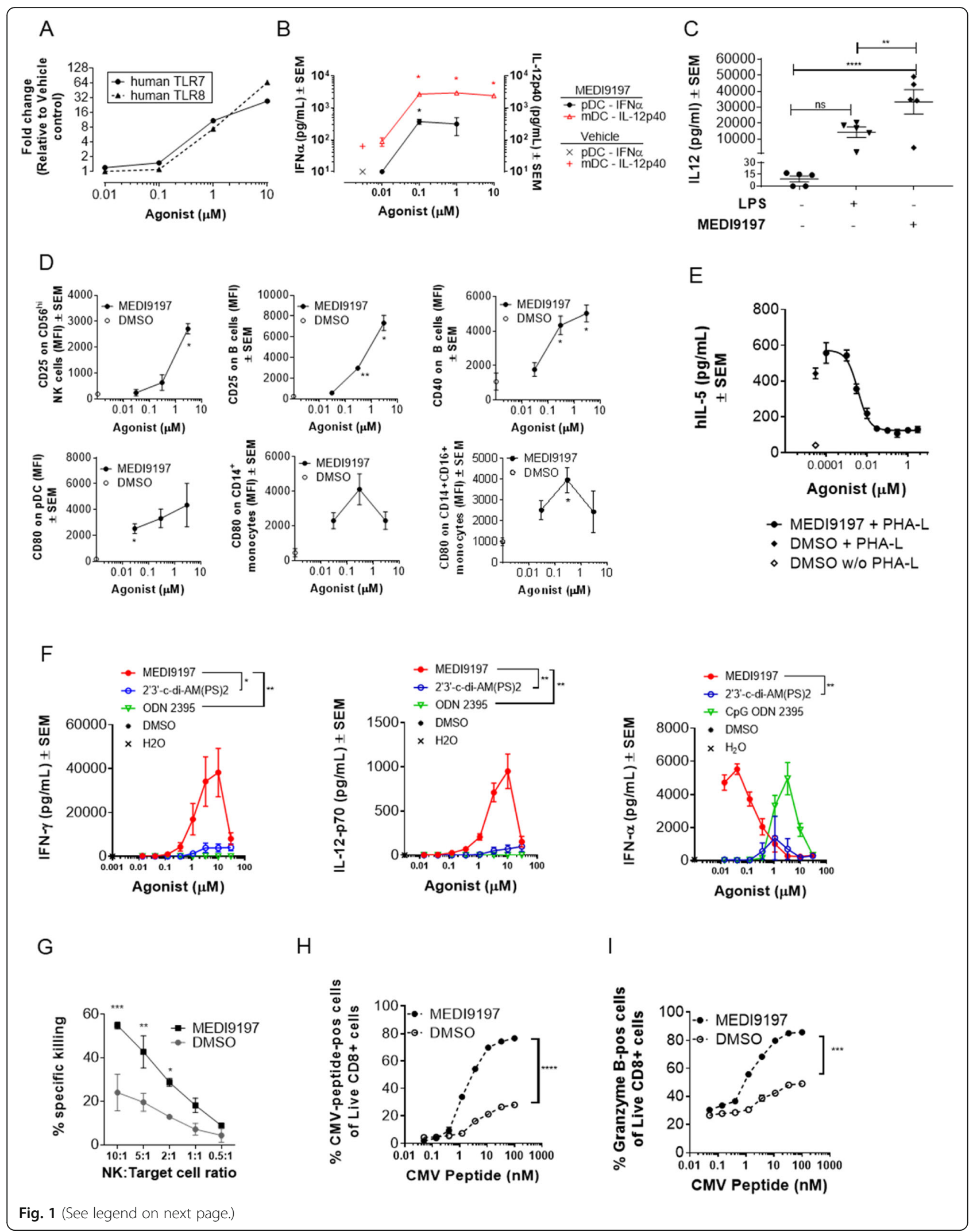




\section{(See figure on previous page.)}

Fig. 1 MEDI9197 activates innate and adaptive immune cells. a SEAP reporter activity in HEK293-NFKB-SEAP cells expressing human TLR7 or TLR8. Results are shown as fold-change relative to DMSO. $\mathbf{b} \mathrm{pDC}$ and $\mathrm{mDC}$ enriched from peripheral blood and treated with MEDI9197 or DMSO. IFN- $\mathbf{a}$ and IL-12p40 secretion was measured from $\mathrm{pDC}$ and $\mathrm{mDC}$, respectively, by ELISA. Results are shown as mean $\pm \mathrm{SEM}, \mathrm{n}=3$ donors. $\mathbf{c} I L-12 \mathrm{p} 70$ cytokine release from $20 \mathrm{ng} / \mathrm{mL}$ LPS or $3 \mu \mathrm{M}$ MEDI9197-treated monocyte derived macrophages was tested by ELISA. Results show the mean of 5 donors. d Median fluorescence intensity (MFI) of activation markers on cell subsets from human PBMCs stimulated with MEDI9197 or DMSO. NK

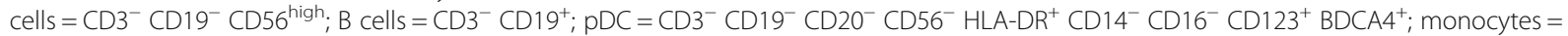
$\mathrm{CD}^{-} \mathrm{CD}^{-} 9^{-} \mathrm{CD}^{-} \mathrm{O}^{-} \mathrm{CD}_{5} 6^{-} \mathrm{HLA}^{-} \mathrm{DR}^{+}$; Data show the mean \pm SEM, representative of 4 donors. e IL-5 release (ELISA) from human PBMCs stimulated with MEDI9197 or DMSO with or without PHA-L. Data show mean of technical triplicates \pm SEM, representative of 9 donors. $\mathbf{f}$ Cytokine production (ELISA and MSD) from human PBMCs stimulated with MEDI9197, C class CpG, or STING agonist. Results show mean \pm SEM of 3 donors, representative of 6 donors. g Percent specific killing of Eu-loaded K562 target cells co-cultured with NK cells isolated from human PBMCs stimulated with MEDI9197 or DMSO. Data show mean of technical duplicates \pm SEM, 9 donors. $\mathbf{h}$ and $\mathbf{i}$ Proportion of CMV peptide-specific CD8 cells (h) or granzyme B-positive CD8 cells (i) after stimulation of PBMCs with MEDI9197 or DMSO and a titration of CMV peptide, 2 donors. Data are representative of $\geq 2$ independent experiments. Statistical analyses were performed by one-way $(C)$ and two-way (F-l) ANOVA with Tukey's (C, $\mathrm{F}, \mathrm{H}, \mathrm{I})$ or Sidak's (G) post hoc test or Welch's upaired T test (one-tailed) $(\mathrm{B}, \mathrm{D}) .{ }^{*} p<0.05,{ }^{* *} p<0.01,{ }^{* * *} P<0.001,{ }^{* * * *} p<0.0001$

mass spectrometry (MS) imaging. MEDI9197 location in a section of excised tumor, indicated in green, was still detectable in concentrated regions of the tumor for at least 8 days post injection (Fig. 2e). The Heme signal is a measure of blood in the tissue slice, related to tissue damage, such as haemorrhage or necrosis. The signal for MEDI9197 does not colocalise with the MS signature for Heme (shown in red), therefore it is unlikely to be localized to a non-viable region of tissue. To determine the time-course of drug retention in B16-F10 tumors, MEDI9197 was quantified in homogenized tumors using HPLC-UV $6 \mathrm{~h}$ to 14 days after injection revealing that approximately $50 \%$ (indicated by dotted line) of the initial dose was retained in the tumor for approximately 9 days post injection (Fig. 2f). These data demonstrate that MEDI9197 is retained at the site of administration for up to 4 weeks after injection, with low systemic exposure.

To further evaluate the immunological effects of MEDI9197 retention at the injection site, naïve mice were SC injected with MEDI9197 or Resiquimod. Expression of TNF $\alpha$, IL-12p40 and IFNץ mRNA was measured in the axilliary and brachial lymph nodes (dLN) proximal to the injection site (Additional file 1: Figure S3). The local dLN response was delayed with MEDI9197 (Tmax 6h) compared to Resiquimod (Tmax $1 \mathrm{~h})$. In the spleen, Resiquimod also induced rapid (Tmax $1 \mathrm{~h}$ ) upregulation of these cytokine transcripts. MEDI9197, however, induced minimal changes in splenic TNF $\alpha$, IL-12p40 and IFNy expression after SC administration (Additional file 1: Figure S3). Thus, local retention of MEDI9197 minimizes distal inflammatory cytokine induction. SC injection of either MEDI9197 or Resiquimod induced expression of type I IFN response related genes (MX1, OAS2, Tnfs10) both in the dLN as well as peripherally in the spleen. However, the Tmax of gene expression for MEDI9197 dosed mice was $6 \mathrm{~h}$, compared with $1 \mathrm{~h}$ for Resiquimod dosed mice (Additional file 1: Figure S3). Overall, these results show that retention of MEDI9197 at the injection site leads to a prolonged localized immune response with minimal systemic exposure or inflammatory cytokine expression.

\section{MEDI9197 induces a range of immunological changes within the tumor microenvironment (TME) resulting in anti-tumor efficacy}

Next, we investigated the effects of MEDI9197 on the TME and growth. MEDI9197, but not Resiquimod, administered IT, on days 8 and 15 post tumor cell implantation, significantly inhibited tumor growth and enhanced long-term survival by 12 days $(p \leq 0.0005)$ in mice bearing established B16-OVA melanoma tumors (Fig. 3a and Additional file 1: Figure S4a). When MEDI9197 was administered to mice SC, on the contralateral flank of the B16-OVA tumor, it was ineffective in mediating tumor control. Therefore, administration and retention of MEDI9197 at the tumor site is required for anti-tumor activity. Repeat dosing or doses higher than $20 \mu \mathrm{g}$ administered IT did not further enhance anti-tumor activity (Additional file 1: Figure S4B-D). Furthermore, we show that IT administration of MEDI9197 can inhibit tumor growth in tumors previously described [25] to have: high (MC38); low (B16-F10 CAG luc2); and suppressive (4 T1) immune cell infiltrates (Fig. 3b). This highlights the potential of IT MEDI9197 to alter a wide range of TMEs to promote anti-tumor immunity. Additionally, imaging of luciferase expression in the B16-F10 CAG luc2 cells as an indicator of tumor burden demonstrates that MEDI9197 is effective at doses of 0.4 or $20 \mu \mathrm{g}$ (Fig. 3c).

Since localization of MEDI9197 in the TME is required for anti-tumor activity, we sought to test the hypothesis that MEDI9197 induces local conversion of the tumor immune infiltrate to promote anti-tumor immunity. Histological examination of B16-OVA tumors, 7 days after MEDI9197 treatment, revealed formation of lymphoid aggregates (ectopic lymph nodelike structure) (Fig. 4a and b) indicative of localised 
A

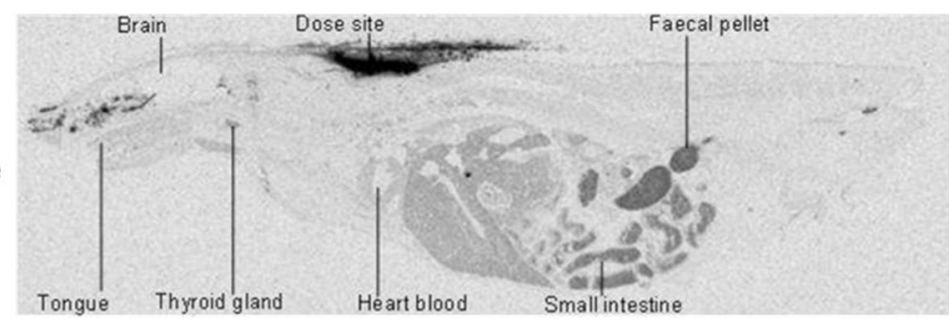

1 day postdose Tongue Thyroid gland Heart blood Smallintestine

28 days postdose

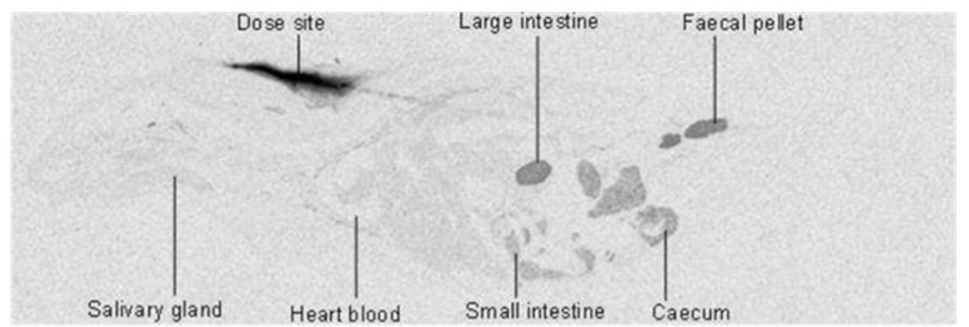

B

C
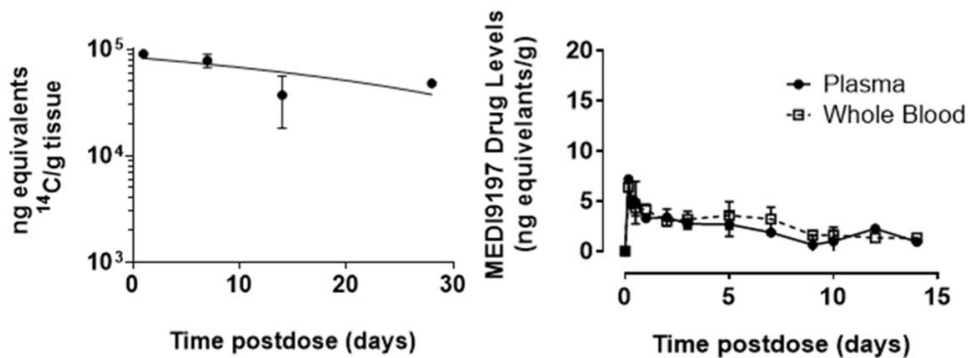

D

$E$

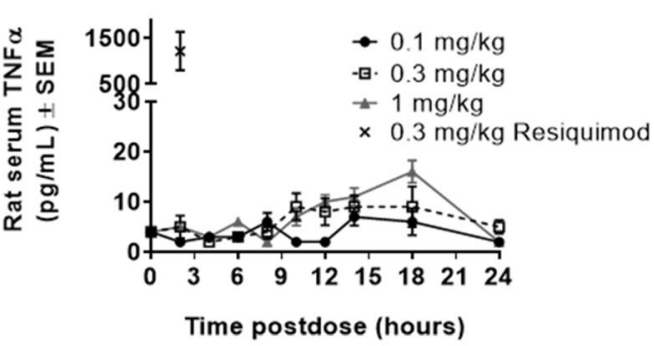

$\mathrm{F}$
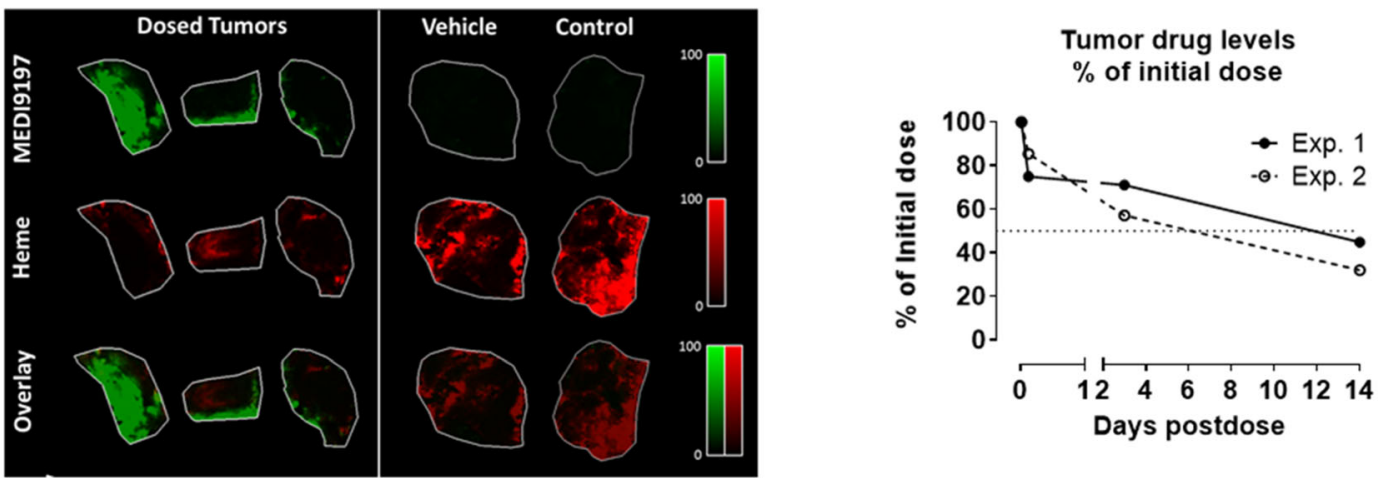

Fig. 2 MEDI9197 is retained locally after injection. a-c Radiolabelled MEDI9197 distribution in male SD rats after SC injection. a, MEDI9197 distribution was measured in tissues by quantitative whole-body autoradiography 1 day and 28 days post-dose. Images of one rat serial transverse section (representative of two rats/time point). $\mathbf{b}$ and $\mathbf{c}$ Quantification of radiolabeled MEDI9197 at the injection site, plasma, and whole blood 4 to $672 \mathrm{~h}$ post-dose (mean, $\mathrm{n}=2$ ). $\mathbf{d}$ Rat serum TNFa levels following a single SC injection of $0.1,0.3$, and $1 \mathrm{mg} / \mathrm{kg}$ MED $19197 \mathrm{or} 0.3 \mathrm{mg} / \mathrm{kg}$ Resiquimod. The values at the $0 \mathrm{~h}$ time point are an average of 30 rats (1 serum sample per rat). The values shown at all other time points are an average of 5 rats (1 serum sample per rat). e MALDI-MSI images showing MEDI9197 and Heme distribution in B16-F10 AP3 tumors after a single $20 \mathrm{\mu g}$ IT dose. Data are representative of 9 mice and 2 independent experiments. $\mathbf{f}$ Drug levels measured by HPLC-UV in B16-OVA tumors, implanted SC in C57BL/6-albino mice. After approximately 15 days, $50 \mu \mathrm{g}$ MEDI9197 was injected IT, and tumors were collected immediately postdose, 6 h, 3 days, and 14 days post-dose (5 mice/time point, 2 independent experiments). Tumor lysate drug levels are expressed as \% of initial dose 


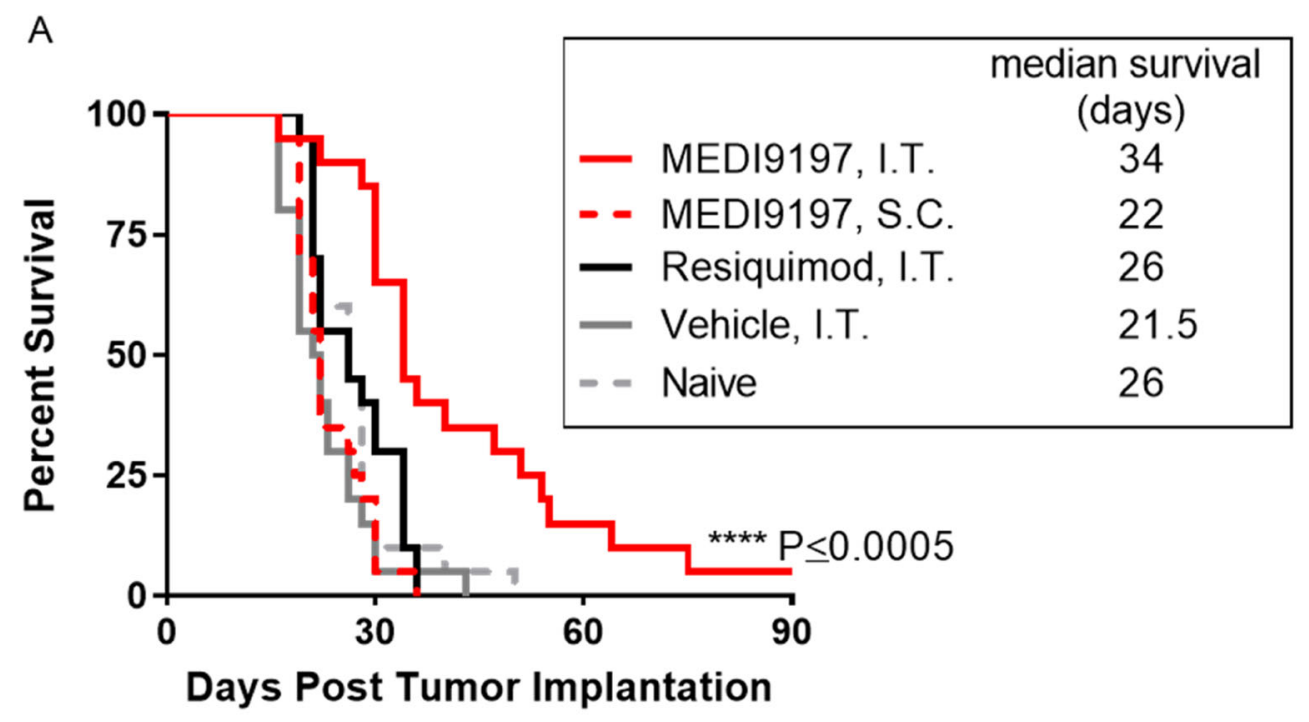

B

$4 \mathrm{T1}$

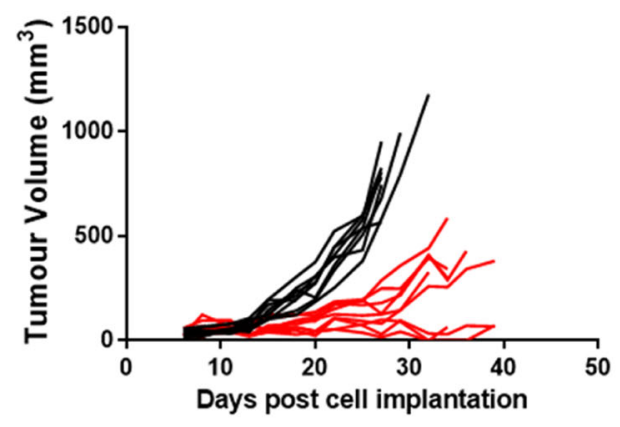

- $20 \mu \mathrm{g}$ MEDI9197 i.t. d7, 14, 22

— Vehicle i.t. d7,14, 22

\section{B16-F10 CAG luc2}

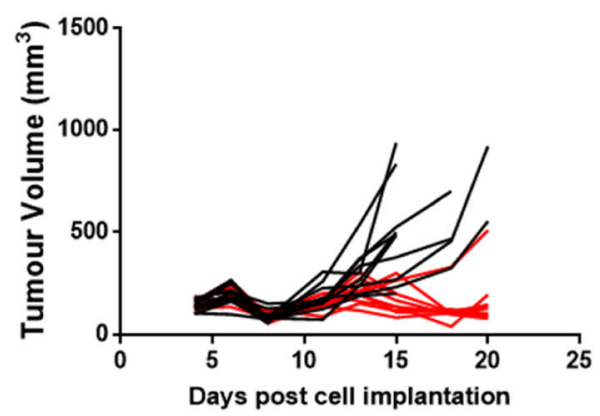

- $20 \mu \mathrm{g}$ MEDI9197 i.t. d5, 12, 19

- vehicle i.t. d5, 12, 19

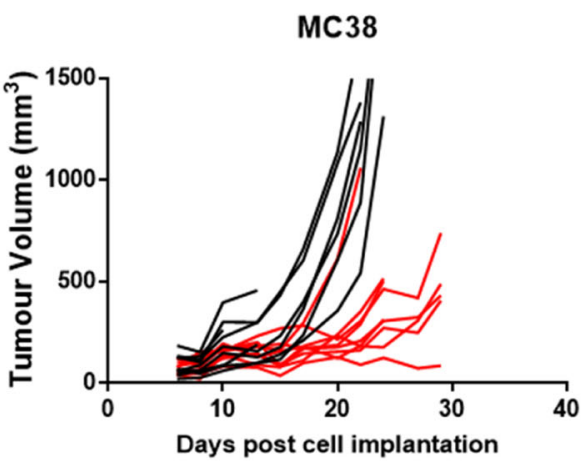

— $20 \mu \mathrm{g}$ MEDI9197 i.t. d9 and 16

— Vehicle i.t. d9 and 16

C

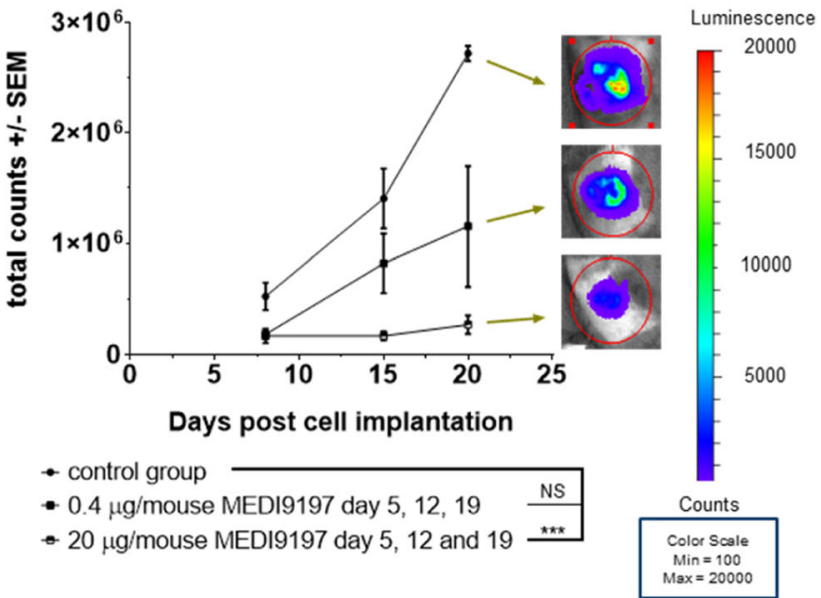

Fig. 3 (See legend on next page.) 
(See figure on previous page.)

Fig. 3 Intratumoral administration is required for MEDI9197 anti-tumor effects and is efficacious in diverse syngeneic models. a Anti-tumor effects was measured in the B16-OVA tumor model following IT injection or SC dosing, away from the tumor on the opposite flank. C57BL/6 J albino mice were implanted SC B16-OVA tumor cells the left flank on Day 0 (20 mice/group). On Days 8 and 15, mice were dosed IT with MEDI9197

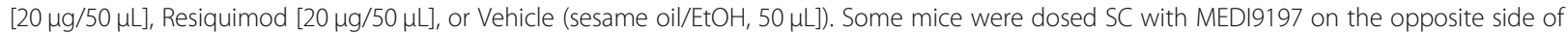
the implanted tumor (right flank). Naîve mice were untreated. Mice were euthanized when tumor size equaled or exceeded $2500 \mathrm{~mm}^{3}$. The Kaplan-Meier plot shows survival for each group up to Day 90. ${ }^{* * * P}<0.0005$; MEDI9197 IT group (solid red line) compared with each of the other groups using the Log-rank test. $\mathbf{b}$ and $\mathbf{c}$. Tumor volume was assessed in 4 T1, B16-F10 AP3 CAG luc2, MC38 single-flank mouse models following IT administration of MEDI9197 (20 $\mu \mathrm{g})$ or Vehicle. MEDI9197 and Vehicle were dosed weekly for 2 or 3 doses as described in the figure. b Spider plots represent tumor volume of individual mice. Vehicle-treated mice are represented with black lines, and MEDI9197-treated mice are represented with red lines. c B16-F10 CAG luc2 tumors (9 mice/group) were treated with either 0.4 or $20 \mu \mathrm{g}$ MEDI9197 weekly on days 5, 12, and 19. D-Luciferin was I.P. injected 15 min prior to imaging bioluminescence on the IVIS100. Data represents the total counts +/- SEM. Statistical analysis was performed by Dunnet's multiple comparisons test. ${ }^{* *} p=0.0004, \mathrm{NS} p=0.1175$. Representative images from day 20 post implantation are shown

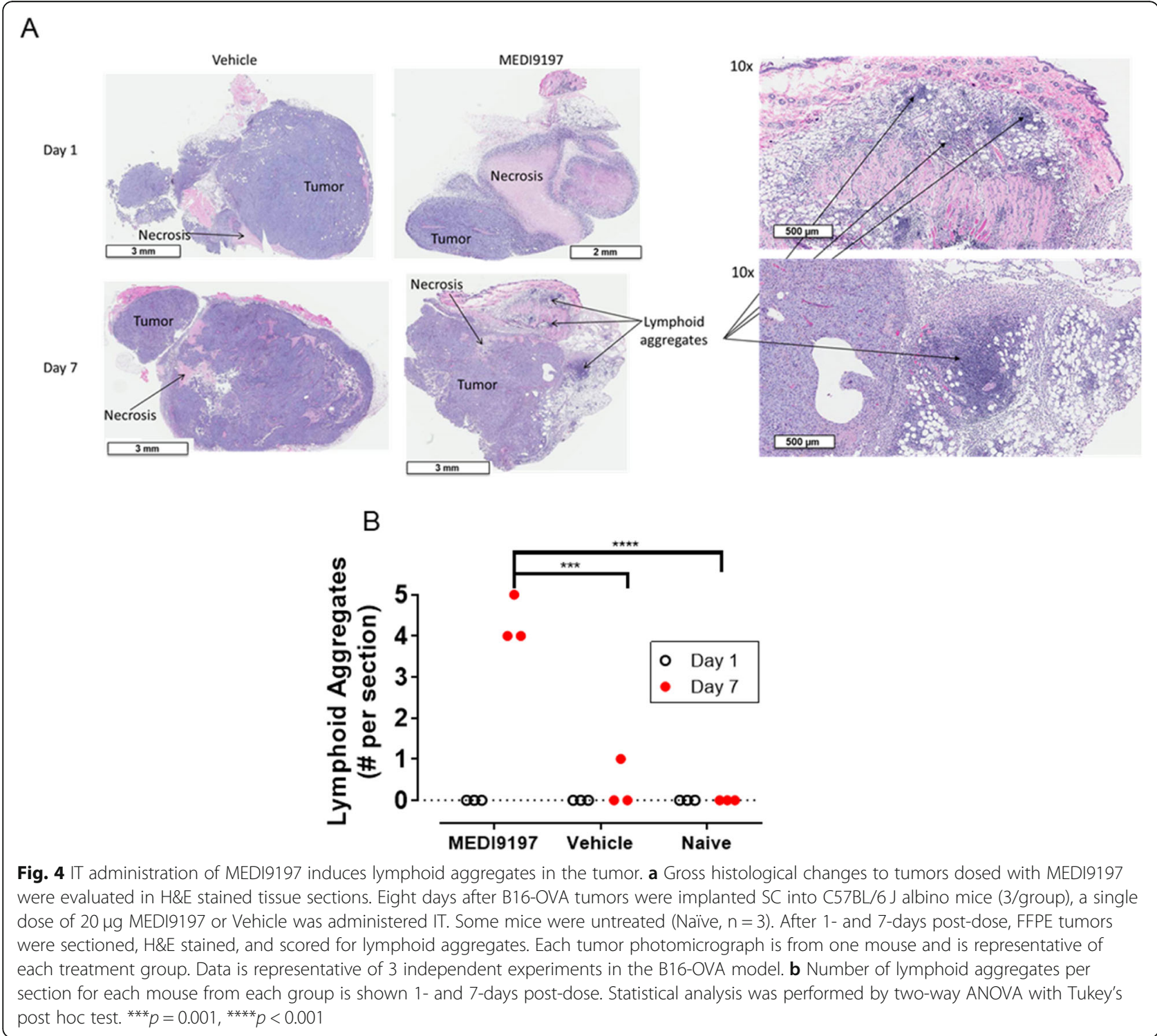




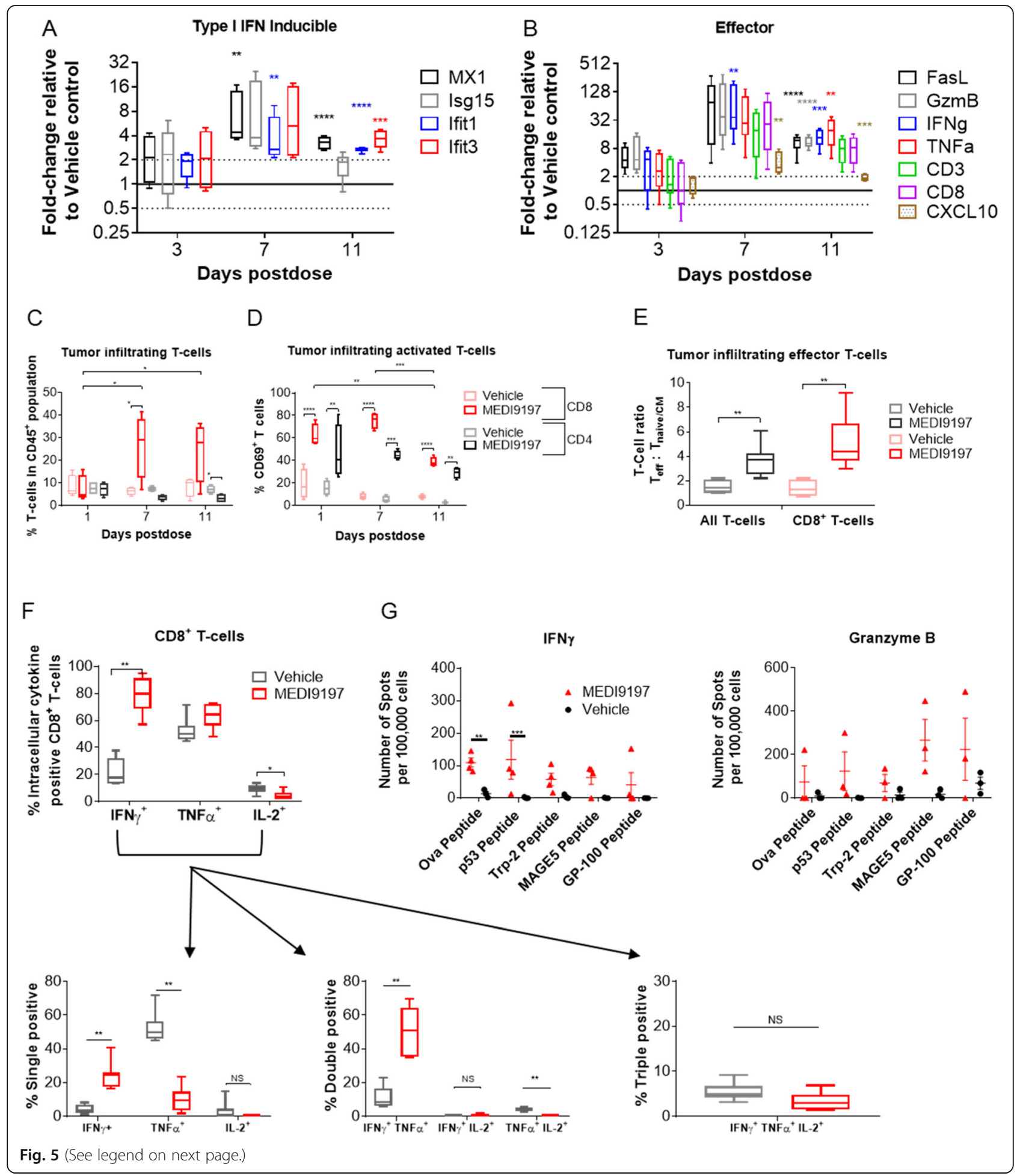

immune responses. In comparison, Vehicle treated or naïve tumors had minimal or no lymphoid aggregates (Fig. 4b).

Gene expression analysis of MEDI9197 treated tumors compared with Vehicle treated tumors showed a strong upregulation of immune related genes in a subset of tumors treated with MEDI9197 (Additional file 1: Figure S5). At 7 and 11 days post-dose, a cohort of mice could be separated based on response to MEDI9197 treatment by tumor size compared with the Vehicle group. Those mice showing drug-induced tumor growth inhibition (tumour volume $<600 \mathrm{~mm}^{3}$, Responders) also correlated 
(See figure on previous page.)

Fig. 5 IT administration of MEDI9197 induces an increase in immune cell activation. SC implanted B16-OVA tumors were injected IT with $20 \mu \mathrm{g}$ of MEDI9197 or Vehicle. The data for all graphs (except G) are shown in box-whiskers plots. Data is representative of at least 2 independent experiments. $\mathbf{a}$ and $\mathbf{b}$ Tumors were collected for qPCR analysis (performed in duplicate) ( $\mathrm{n}=5$ per group). The data indicate fold-change in gene expression, relative to Vehicle, associated with type I IFN inducible (A) or T cell effector (B) genes. $\mathbf{c}-\mathbf{d}$, Percentage of T cells (CD3 $\varepsilon^{+} / \mathrm{CD} 4^{+}$or $\left.\mathrm{CD} 8 \mathrm{a}^{+}\right)$in the $\mathrm{CD}^{+} 5^{+}$population and of activated T cells $\left(\mathrm{CD}^{\circ} 9^{+}\right)$assessed by flow cytometry in individual tumors after MEDI9197 and Vehicle dosing ( $n=4$ mice/treatment group/day). e Ratio of effector $T$ cells $\left(T^{\text {eff }}: C D 45^{+} / T C R \beta^{+} / C D 44^{+} / C D 62 L^{-}\right)$and naïve/central memory $T$ cells $\left(\mathrm{T}^{\text {naive/CM}}\right.$ : $\left.\mathrm{CD} 45^{+} / \mathrm{TCR} \beta^{+} / \mathrm{CD} 44^{+/-} / \mathrm{CD} 62 \mathrm{~L}^{+}\right)$for total T cells and $\mathrm{CD} 8^{+}$cells $\left(\mathrm{CD} 45^{+}, \mathrm{TCR} \beta^{+}, \mathrm{CD} 8 \mathrm{a}^{+}\right)$, measured by flow cytometry in tumors injected with MEDI9197 $(n=11)$ or Vehicle $(n=7)$ and collected 6-8 days post-dose. $\mathbf{f}$ The top graph shows the percentage of intracellular cytokines in

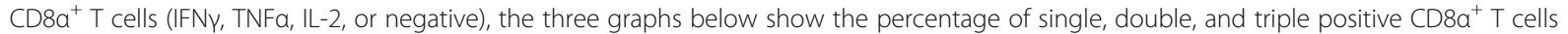
from tumors collected $4-5$ days post dosing with MEDI9197 $(n=7)$ and Vehicle $(n=6)$. Cytokines were analyzed by flow cytometry in PMA/ ionomycin stimulated $\mathrm{CD}_{4} 5^{+}$enriched cells. $\mathbf{g}$ TILs were isolated from each tumor 11 days post-dose ( $\left.\mathrm{n}=3-4 / \mathrm{group}\right)$ and used for ELISpot analysis for IFNy and Granzyme B following stimulation with PMA/lonomycin or class I-restricted peptides $\left(\mathrm{H}-2 \mathrm{~K}^{\mathrm{b}}\right.$ or $\left.\mathrm{H}-2 \mathrm{D}^{\mathrm{b}}\right)$. The results show the number of spots per 100,000 cells after background subtraction based on control peptide ( $\mathrm{H}-2 \mathrm{D}^{\mathrm{b}}$ and $\left.\mathrm{H}-2 \mathrm{~K}^{\mathrm{b}}\right)$ stimulated TILs. Statistical analyses were performed using multiple T tests of dCT values (a, b), 2-way ANOVA ( $c, d$, and g) with Sidak's multiple comparisons test (c, d), and the Mann Whitney test (e, f). ${ }^{*} p<0.05,{ }^{* *} p<0.01,{ }^{* * *} p<0.001,{ }^{* * *} p<0.0001$

with the subset of tumors with a strong upregulation of immune related genes in contrast to those with no tumor growth inhibition which were similar to Vehicle control group, Non-responders. To better understand the mechanism of action for MEDI9197 anti-tumor activity, tumors that are responding to MEDI9197 treatment, based on tumor size compared with Vehicle, were used for pharmacodynamic analyses, where possible.

We went on to characterize the changes in the immune phenotype of the TME. MEDI9197 treatment quickly induces a type I IFN response demonstrated by an increase in IFN-inducible genes (e.g. Mx1, Isg15, Ifit1 and Ifit3, Fig. 5a), which were increased at 3 days and peaked at 7 days post-dose. Expression of $\mathrm{CD}^{+} \mathrm{T}$ cell response genes (e.g. FasL, GzmB, and IFNg, Fig. 5b) peaked at 7 days post-dose and remained elevated at 11 days post-dose (e.g. IFN $\gamma$ was approximately 32-fold and 15-fold higher than Vehicle control, respectively). Furthermore, the proportion of TILs made up by $\mathrm{CD} 8^{+} \mathrm{T}$ cells significantly increased 7 days and 11 days after MEDI9197 treatment $(\mathrm{p}=0.0132$ and $\mathrm{p}=0.0589$, respectively, compared with vehicle treatment), whereas the relative abundance of $\mathrm{CD}^{+} \mathrm{T}$ cells was decreased 11 days post-dose (Fig. 5c, Additional file 1: Figure S6B). Additionally, MEDI9197 enhanced activation of both $\mathrm{CD} 4^{+}$and $\mathrm{CD} 8^{+} \mathrm{T}$ cells at all timepoints tested (increased $\% \mathrm{CD} 9^{+}$cells observed 1 day, 7 day and 11 days post-dose, Fig. 5d, Additional file 1: Figure S6B). NK cell activation in the tumor followed the same kinetics as $\mathrm{T}$ cell activation, but unlike $\mathrm{CD} 8^{+}$ $\mathrm{T}$ cells, MEDI9197 did not increase the proportion of NK cells in the tumor (Additional file 1: Figure S6A and B). Overall, these results indicate that a single IT dose of MEDI9197 induces T cell and NK cell activation beginning 1 day after treatment and lasting at least 11 days post-dose and drives a significant increase in the relative abundance of $\mathrm{CD}^{+} \mathrm{T}$ cells at later timepoints.
We have observed that MEDI9197 can enhance human NK cell killing of target cells (Fig. 1) and can induce NK cell activation in vivo (Additional file 1: Figure S6A), whereas Singh et al. [23] have previously demonstrated that MEDI9197 anti-tumor activity is dependent on $\mathrm{CD}^{+} \mathrm{T}$ cells, but not NK cells, using depletion studies in the B16-OVA model, suggesting NK cells may be involved but are not required for the anti-tumor activity observed in the B16-OVA model, so we focused on further evaluation of the functional status of TILs. MEDI9197 induced an increase in total effector T cells (ratio of $\mathrm{T}^{\text {eff }}\left(\mathrm{CD} 45^{+} / \mathrm{TCR} \beta^{+} / \mathrm{CD} 44^{+} / \mathrm{CD} 6 \mathrm{~L}^{-}\right)$to $\mathrm{T}^{\text {nai- }}$ ve/CM $\left(\mathrm{CD} 45^{+} / \mathrm{TCR} \beta^{+} / \mathrm{CD} 44^{+/-} / \mathrm{CD} 62 \mathrm{~L}^{+}\right)$and effector $\mathrm{CD}^{+}{ }^{-} \mathrm{T}$ cells (ratio of $\mathrm{CD} 45^{+} / \mathrm{TCR} \beta^{+} / \mathrm{CD} 8 \alpha^{+} / \mathrm{CD} 44^{+} /$ $\mathrm{CD} 2 \mathrm{~L}^{-}$to $\mathrm{T}^{\text {naive/CM}}$ ) in the tumor 6-8 days after dosing (Fig. 5e, Additional file 1: Fig. 6e). In keeping with the induction of IFN $\gamma$ gene expression in the TME detected by qPCR 7 days post-dose (Fig. 5b), MEDI9197 dosing induced a significant increase in the proportion of $\mathrm{CD}^{+}$ $\mathrm{T}$ cells expressing IFN $\gamma$ compared to the Vehicle group ( $\mathrm{p}<0.0001 ; 79.8 \%$ versus $17.6 \%$ ) following ex vivo stimulation with PMA/ionomycin (Fig. 5f, Additional file 1: Figure S6D). The lower panels in Fig. $5 \mathrm{f}$ indicate that MEDI9197 induces significantly more double-positive $(\mathrm{IFN} \gamma / \mathrm{TNF} \alpha) \mathrm{CD}^{+} \mathrm{T}$ cells compared to the Vehicle group ( $\mathrm{p}=0.0041$; approximately $60 \%$ versus $10 \%$ ). In contrast, most (about $70 \%$ ) of the Vehicle-treated CD8 ${ }^{+}$ $\mathrm{T}$ cells were single-positive (TNF $\alpha)$. There was no significant difference in the percentage of triple-positive (IFN $\gamma / \mathrm{TNF} \alpha / \mathrm{IL}-2) \mathrm{CD}^{+} \mathrm{T}$ cells with MEDI9197 compared with Vehicle treatment. Eleven days post-dose, $\mathrm{T}$ cells from the tumor were responsive to multiple tumor associated antigens as demonstrated by IFN $\gamma$ and granzyme B release after ex vivo stimulation with OVA or melanoma associated peptides (p53, TRP-2, gp100 and MAGE-A5) (Fig. 5g). These data indicate MEDI9197 induced upregulation of type I IFN response, IFN $\gamma$, and $\mathrm{CD}^{+} \mathrm{T}$ cell activation, all indicators of conversion to a hot TME favourable for anti-tumor immunity. 


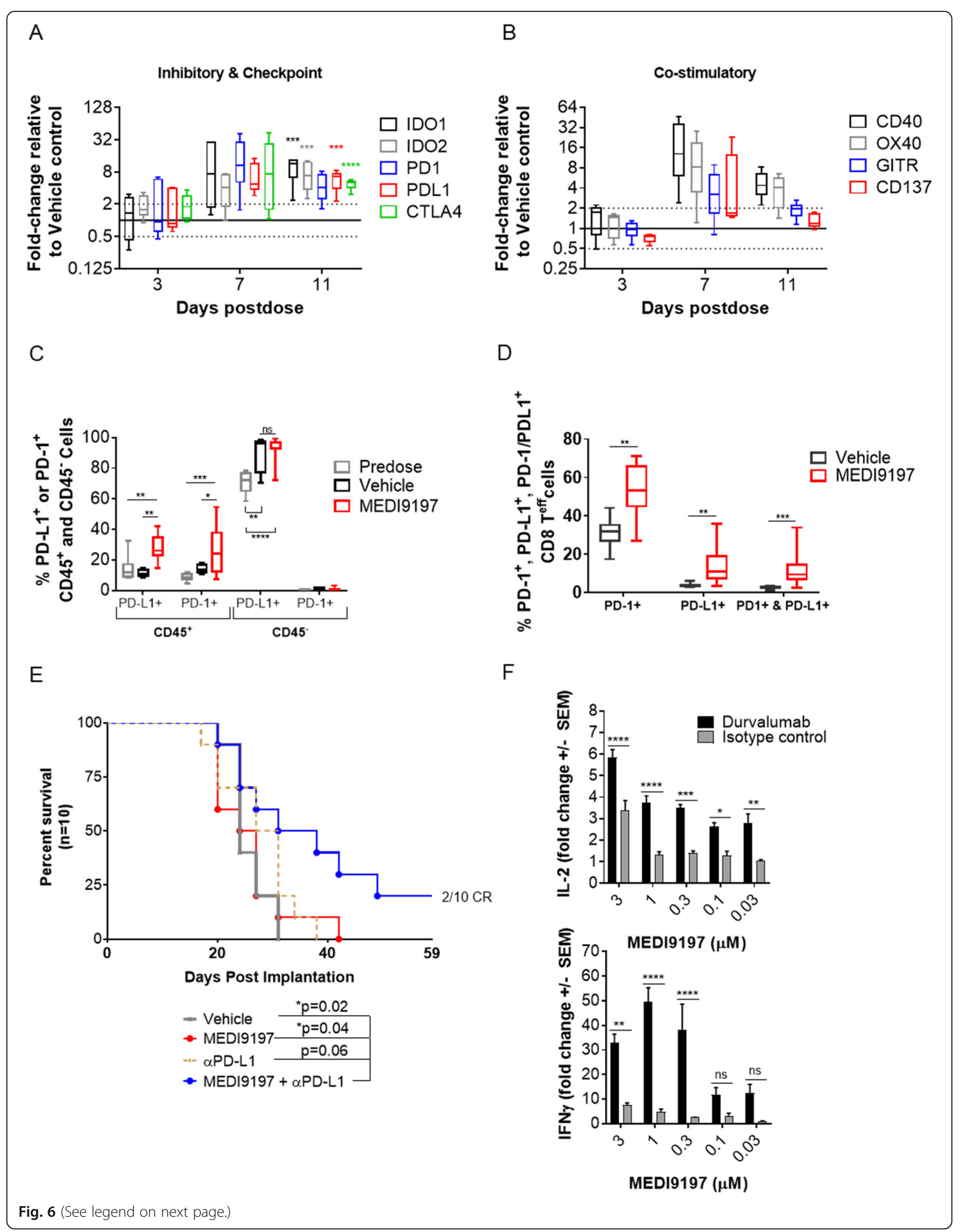




\section{(See figure on previous page.)}

Fig. 6 MEDI9197 enhances expression of PD1/L1 and increases immune stimulatory and anti-tumor effects of PD-L1 blockade. a and $\mathbf{b}$ The tumor immune profile was evaluated by qPCR following IT dosing. B16-OVA tumors were collected 3, 7, and 11 days post IT dose (20 $\mathrm{\mu g}$ MED19197 or Vehicle, $n=5$ ). Total RNA was processed from each tumor, as described in Fig. 5a. The data indicate fold-change in gene expression associated with (a) Inhibitory and Checkpoint, and (b) Co-stimulatory genes. Fold-change is relative to the Vehicle group. Day 6-11 post MEDI9197 treatment results are enriched for responders. Multiple T tests were performed using dCT values to compare MEDI9197 treated versus Vehicle group $(\mathbf{a}, \mathbf{b})$. c-d Percentage of PD- $1^{+}$and/or PD-L1 ${ }^{+}$populations from tumor cells, TILs $\left(C D 45^{+}\right)(\mathbf{c})$, and effector $\mathrm{CD} 8 \mathrm{a}^{+}$cells $\left(\mathrm{CD} 45^{+}\right.$/ $\left.\mathrm{TCRB}^{+} / \mathrm{CD} 8 \mathrm{a}^{+} / \mathrm{CD} 44^{+} / \mathrm{CD} 2 \mathrm{~L}^{-}\right)$(d) measured by flow cytometry in tumors 6-8 days post-dose of MEDI9197 $(n=11)$ or Vehicle $(n=7)$. Statistical analysis used 2-way ANOVA with Tukey's multiple comparisons test (c) and Mann-Whitney test (unpaired, non-parametric $t$ test) (d). Data is representative of at least two independent experiments. e Kaplan-Meier plots of survival in the B16-OVA tumor model following MEDI9197 and anti-PD-L1 treatment. C57BL/6 albino mice ( $n=10$ /group) were implanted SC in the right flank with B16-OVA tumors on day 0. On day 10, mice were dosed IT with $20 \mu \mathrm{g}$ MEDI9197 or Vehicle, and twice weekly for 6 doses IP with $200 \mu \mathrm{g}$ of anti-PD-L1 Ab or isotype control. CR, complete responder. Statistical analysis was performed using the Log-rank (Mantel-Cox) test. f Cytokine production after 3 (IL-2) and 5 (IFNY) days of coculture of allogeneic T cells with human Mo-DCs (10:1 ratio). DCs were primed for $18 \mathrm{~h}$ with a titration of MEDI9197 before medium change and addition of T cells plus $100 \mathrm{nM}$ Durvalumab or NIP228 isotype control. Data are representative of 4 donors and statistical analysis was performed using two-way ANOVA with Bonferroni post-test. ${ }^{*} p<0.05$, ${ }^{* *} p<0.01$, ${ }^{* *} p<0.001$, ${ }^{* * *} p<0.0001$

\section{MEDI9197 enhances activity of IO therapies}

The robust localized activation of immune cells and further recruitment of $\mathrm{CD}^{+}$TILs following MEDI9197 IT dosing indicates that this approach may compliment other IO therapies. We found that MEDI9197 induces an increase in gene expression for immune inhibitory (e.g. PD-1, PD-L1) and T cell co-stimulatory molecules (e.g. GITR and OX40) in the injected tumor (Fig. 6a and b). Based on the ability of MEDI9197 to induce $\mathrm{CD}^{+} \mathrm{T}$ cell activation and IFN $\gamma$ production, as well as the increase in PD-1 and PD-L1 gene expression observed in the tumor after MEDI9197 treatment (Fig. 6a), it is not surprising that MEDI9197 also induced a significant increase in surface PD-1 expression on TILs, especially $\mathrm{CD}^{+} \mathrm{T}$ cells $\left(\mathrm{p}<0.05\right.$ on $\mathrm{CD} 45^{+}$cells and $\mathrm{p}=0.0059$ on $\mathrm{CD}^{+}$effector T cells; Fig. $6 \mathrm{c}$ and d, Additional file 1: Figure S6C). MEDI9197 also induced a significant increase in PD-L1 on TILs including $\mathrm{CD}^{+} \mathrm{T}$ cells $(\mathrm{p}<$ 0.01 on $\mathrm{CD}_{4} 5^{+}$cells and $\mathrm{p}=0.0012$ on $\mathrm{CD} 8^{+}$effector $\mathrm{T}$ cells). Although a greater proportion of $\mathrm{CD}^{+} \mathrm{T}$ cells in the MEDI9197 group expressed cell surface PD-1 compared to PD-L1 (50\% versus 10\%), there were more $\mathrm{CD}^{+} \mathrm{T}$ cells in MEDI9197-treated tumors that expressed both cell surface PD-1 and PD-L1 (about 10\% compared to $1 \%$ in the Vehicle group).

Given the increase in co-stimulatory or inhibitory molecules following IT dosing with MEDI9197 we explored whether combining MEDI9197 with T cell targeted therapies would result in enhanced antitumor efficacy. Similar to previous reports in the B16-F10 model [23], we found that MEDI9197 increases median survival observed with anti-PD-L1 $\mathrm{mAb}$ in the B16-OVA model from 29 to 34.5 days (Fig. 6e) and resulted in 2 out of 10 tumors regressing without regrowth for 59 days post tumor cell implantation, so we extended these findings to a human co-culture in vitro assay. Using a primary human DC-T cell mixed lymphocyte reaction (MLR) assay, we show that combining a PD-L1 blocking
mAb (MEDI4736, durvalumab) with MEDI9197 increased IL-2 and IFN $\gamma$ cytokine production versus MEDI9197 alone (Fig. 6f).

To examine the combination potential of MEDI9197 with $\mathrm{T}$ cell co-stimulatory molecules, an OX40 agonist mAb or GITRL fusion protein (FP) was combined with a suboptimal dose of MEDI9197 in the B16-OVA model. While neither the OX40 agonist mAb, GITRL FP, nor MEDI9197 was efficacious as a monotherapy, significant tumor growth inhibition was observed when combining MEDI9197 administered IT with systemic administration of an anti-OX40 agonist ( $\mathrm{p}=0.005$; compared with anti-OX40 alone) or a GITRL FP agonist ( $\leq \leq 0.0001$; compared with GITRL FP alone) (Fig. 7).

\section{Discussion}

We report here that MEDI9197 is a TLR7/8 agonist driving robust activation of human adaptive and innate immune cells including both $\mathrm{mDC}$ and $\mathrm{pDC}$. Like TLR7/8 agonists, TLR9 agonists and STING agonists delivered IT also promote anti-tumor immunity in mouse models [19, 30], and are currently being investigated in clinical trials (NCT02675439, NCT03172936, NCT02254772). However, we report here that these agonists have different effects on human immune cells. In particular, MEDI9197 activates human immune cells to secrete IFN $\alpha$, IL-12 and IFN $\gamma$, whereas TLR9 and STING agonists only induced IFN $\alpha$ from human PBMC. Together this broader cytokine profile may be more effective at enhancing $\mathrm{CD}^{+} \mathrm{T}$ cell responses whilst inhibiting MDSC and Treg cells. Note that TLR9 is not expressed in human monocytes and myeloid dendritic cells, unlike TLR7 and TLR8 [31], which in part may explain the reduced ability of TLR9 ligands to enhance CD8 T cell responses in humans [32].

Despite the potent anti-tumor activity of systemic TLR agonists in pre-clinical models, clinical development of these agents has been hampered by the induction of CRS, and a lack of efficacy at tolerated doses [4, 10, 11, 33-38]. We report here that the unique structure and formulation 


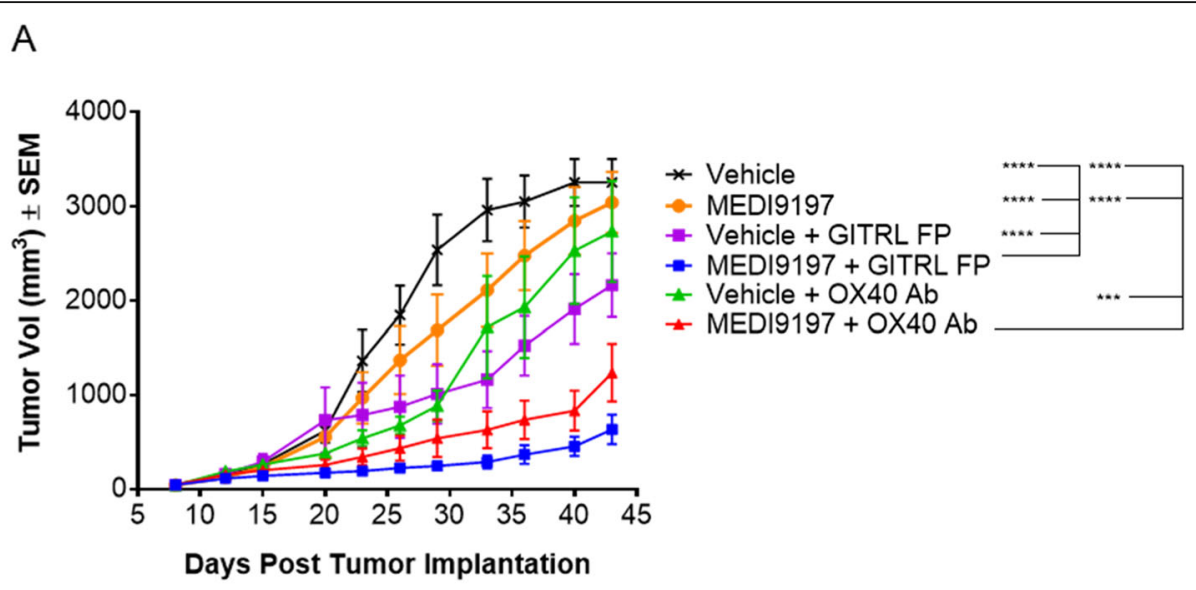

B

Vehicle

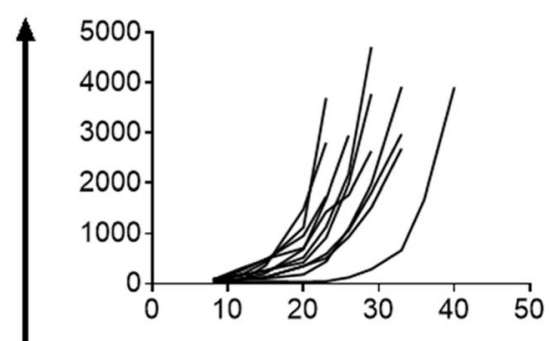

Vehicle + OX40 Ab

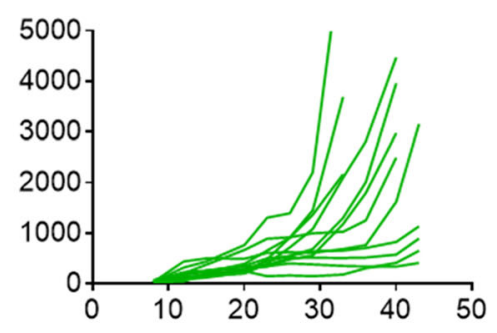

1

Eี
Vehicle + GITRL FP

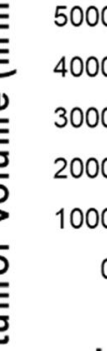

days post tumor implantation

MEDI9197

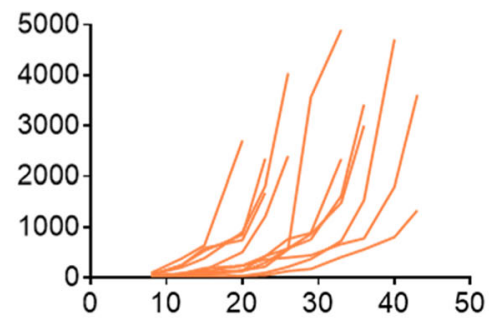

MEDI9197 + OX40 Ab

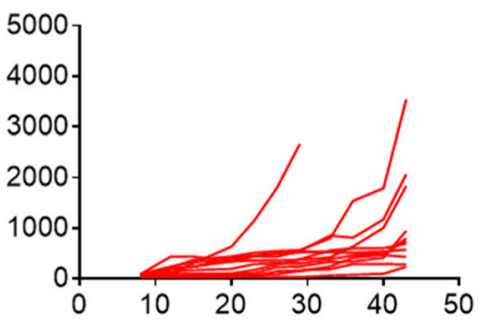

MEDI9197 + GITRL FP

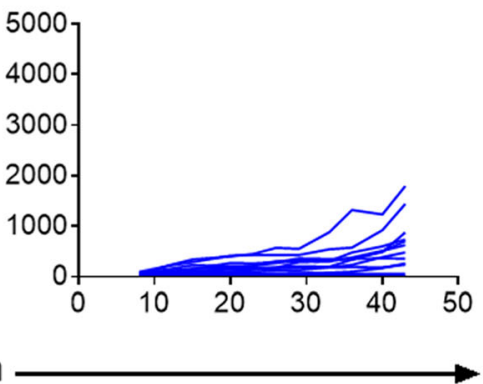


(See figure on previous page.)

Fig. 7 MEDI9197 enhances efficacy when combined with I-O agents targeting OX40 or GITR. Tumor growth was measured in the single-flank B16-OVA tumor model following IT injection of MEDI9197 and IP dosing with GITRL FP or OX40 antibody. C57BL/6 J albino mice ( $\mathrm{n}=11$-12/ group) were implanted SC in the right flank with B16-OVA tumors on Day 0. On Days 8 and 15, mice were dosed IT with $0.4 \mu \mathrm{g} \mathrm{MEDI9197} \mathrm{or}$ Vehicle, and dosed IP with $25 \mathrm{mg} / \mathrm{kg}$ GITRL FP or $12 \mathrm{mg} / \mathrm{kg}$ OX40 Ab. a Tumor volume as a mean (with last observation carried forward) \pm SEM up to Day 43 and (b) spider plots of individual tumor volume. Statistical analysis was performed using two-way ANOVA with Tukey's multiple comparisons test. ${ }^{* *} p=0.0005,{ }^{* * * *} p=0.0001$

of MEDI9197 enables it to be retained within the tumor after IT delivery, minimising systemic drug exposure and cytokine release, and driving sustained local TLR7/8 activation in the TME. It is likely that the limited changes in circulating TNF $\alpha$ cytokine levels observed following local MEDI9197 treatment were due to "spill over" of cytokines released from local immune cells at the injection site, since no systemic TNF $\alpha$ gene expression was detected in the spleen. Furthermore, retention and prolonged immune activation in the tumor by MEDI9197 appear critical for its anti-tumor activity, since IT delivery of Resiquimod, which rapidly disseminates and leads to systemic immune activation, failed to drive anti-tumor activity. Similarly, SC delivery of MEDI9197 at a site distal to the tumor was ineffective. The variability in dose retention (such as local dissemination at the treatment site) and the local immune milieu at the injection site may account for the variability observed in response to MEDI9197.

Positive responses to ICB therapy in patients has been shown to correlate with $\mathrm{CD}^{+} \mathrm{T}$ cell infiltration [3]. Tumors with low $\mathrm{T}$ cell infiltrate represent a significant unmet need. We report that activation of TLR7/8 in the tumor results in sustained transformation of the TME. In particular, MEDI9197 induced increased immune infiltration and the formation of ectopic lymph node structures in B16-OVA tumors. Type I IFN response genes were upregulated, $\mathrm{CD} 8^{+} \mathrm{T}$ cell infiltration was enhanced, and these cells were activated, expressing IFN $\gamma$. These data showing increased presence of $\mathrm{CD}^{+} \mathrm{T}$ cells and IFN $\gamma$ suggest MEDI9197 IT delivery induces TME conversion to a hot immune phenotype. A similar inflammatory influx also correlated with tumor regression in response to topical Aldara (5\% Imiquimod cream) in patients [39]. We have also shown increased NK cell killing of target cells and increased expression of CD69 on NK cells from mouse TILs, suggesting a role for NK cells in the anti-tumor activity of MEDI9197, which warrants further investigation.

The ability of MEDI9197 treatment to convert tumors from 'cold' to 'hot' make it an attractive co-therapy for ICB. PD-1, PD-L1, and CTLA4 and co-stimulatory molecules CD40, GITR, and OX40 are potential targets since MEDI9197 upregulates their expression in the TME. Our results confirm previous work demonstrating enhanced anti-tumor immunity in preclinical mouse models to the combination of MEDI9197 with PD-L1 blocking antibodies [23]. Furthermore, we go on to show combining MEDI9197 with PD-L1 blockade enhanced IFN $\gamma$ production in a human DC/T cell MLR assay strengthening the rationale for combining MEDI9197 with ICB therapies targeting PD-1/PD-L1 interactions. The combination of MEDI9197 with GITRL FP or OX40 mAb also enhanced anti-tumor activity in the B16-OVA model. Studies in additional syngeneic models might provide insight into how different TMEs would impact on the activity of these combinations. These data are in agreement with the recent findings of Sagiv-Barfi et al [40] that in situ vaccination of an OX40 agonist with either TLR9 agonist SD-101 or Resiquimod resulted in an enhanced systemic anti-tumor immune response. Similar to our observations with MEDI9197, they also observe an increase in OX40 expression after intratumoral injection of SD-101. Beyond T cell-targeted therapies, others have also reported that MEDI9197 combination with $\mathrm{CpG}$ ODN enhanced antitumor immunity in mouse models. [24]. In addition, combinations of MEDI9197 with standard of care treatments for cancer, such as chemotherapy and radiotherapy, that drive release of tumor antigens are attractive given the observed vaccine adjuvant activity of MEDI9197 [22, 41-43]. Indeed, TLR7 agonists have previously been reported to enhance efficacy in combination with radiotherapy and chemotherapy in syngeneic mouse tumor models [44, 45].

\section{Conclusions}

MEDI9197 is a TLR7/8 agonist that promotes robust and broad activation of human immune cells. MEDI9197 is uniquely retained at or near the site of injection to cause prolonged immune activation within the TME and in the local draining lymph nodes. IT injection of MEDI9197 results in tumor regression and enhanced survival in multiple mouse tumor models. IT therapy with MEDI9197 dramatically alters the TME by increasing $\mathrm{CD}^{+} \mathrm{T}$ cell infiltration and activation, increasing anti-tumor cytokines, and upregulating immune checkpoint expression. Combining MEDI9197 with other immune-modulatory agents can enhance anti-tumor activity, suggesting several routes to explore the utility of MEDI9197 in the clinic. MEDI9197 has been evaluated in Phase I clinical trials. 


\section{Additional file}

Additional file 1: Supplementary Information Materials and Methods. Figure S1 In vitro characterisation of MEDI9197. Figure S2 Rat serum MEDI9197 levels following SC or IM administration. Figure S3 Local versus systemic cytokine induction following MED19197 administration in rodents. Figure S4 Intratumoral administration is required for MED19197 anti-tumor effects. Figure S5 IT administration of MEDI9197 modifies the tumor immune gene profile. Figure S6 MEDI9197 enhances NK activation and gating strategies. (DOCX $1080 \mathrm{~kb}$ )

\section{Abbreviations}

APC: Antigen presenting cell; CRS: Cytokine release syndrome; dLN: Axilliary and brachial lymph nodes; FP: Fusion protein; ICB: Immune checkpoint blockade; IM: Intramuscular; IP: Intraperitoneal; IT: Intratumoral; mAbs: Monoclonal antibodies; mDC: Myeloid dendritic cells; MEC: Minimum effective concentration; MLR: Mixed lymphocyte reaction; mo-DC: Monocyte-derived DC; NK: Natural killer; PD: Pharmacodynamic; pDC: Plasmacytoid dendritic cells; QRA: Quantitative radiochemical analysis; QWBA: Quantitative whole-body autoradiography; SC: Subcutaneous; STING: Stimulator of interferon genes; TILs: Tumor infliltrating lymphocytes; TLR: Toll-like receptor; TME: Tumor microenvironment

\section{Acknowledgements}

The core tissue culture facility and Clinical Pharmacology and Safety Science unit of AstraZeneca Ltd., Cambridge, UK, and the Veterinary Services unit of 3M Company, St. Paul, USA.

\section{Authors' contributions}

Conception and Design: SRM, JPV, KD, IG, PG, ZC, SJD, AJD, NL, RH, MAT, RWW. Development of methodology: SRM, JPV, KD, IG, PG, JJ, MJE, JS, ET, JE, AT, RG. Acquisition of data: SRM, JPV, KD, IG, PG, JJ, MJE, JS, ET, AT. Analysis of data: SRM, JPV, KD, IG, PG, MJE, JS, ET, ZC, SJD, AJL, NL, JE, AT, RG, RH, MAT, RWW. Writing, review and/or revision of the manuscript: SRM, JPV, KD, IG, PG, MJE, JS, ET, ZC, SJD, AJL, NL, RH, MAT, RWW. All authors read and approved the final manuscript.

\section{Funding}

The work was supported by AstraZeneca Ltd

\section{Availability of data and materials}

The datasets used and/or analysed during the current study are available from the corresponding author on reasonable request.

\section{Ethics approval and consent to participate}

In vivo experiments were either conducted in an Association for Assessment and Accreditation of Laboratory Animal Care (AAALAC)-accredited and United States Department of Agriculture (USDA)-licensed facility under sterile and standardized environmental conditions, or in accordance with the UK Home Office guidelines, including local ethical review, and the Animals (Scientific Procedure) Act 1986/Directive 2010/63/EU.

\section{Consent for publication}

Not applicable

\section{Competing interests}

SRM, KD, SR, MJE, ET, JS, RG, SJD, NL, RH, and RWW are employees of AstraZeneca. JPV, IG, PG, JJ, JE, AT and MT are employees of $3 \mathrm{M}$.

\section{Author details}

${ }^{1}$ R\&D Oncology, AstraZeneca Ltd, Aaron Klug Building, Granta Park, Cambridge CB21 6GH, UK. ${ }^{2} 3 \mathrm{M}$ Drug Delivery Systems Division, 3M Center Bldg 260-3A-14, St. Paul, MN 55144, USA. ${ }^{3}$ R\&D Oncology, AstraZeneca Ltd, 1 Medlmmune Way, Gaithersburg, MD 20878, USA. ${ }^{4}$ R\&D Biopharmaceuticals, Pathology, Drug Safety and Metabolism, AstraZeneca Ltd, Cambridge, UK.
Received: 1 April 2019 Accepted: 28 August 2019

Published online: 11 September 2019

\section{References}

1. Pardoll DM. The blockade of immune checkpoints in cancer immunotherapy. Nat Rev Cancer. 2012;12(4):252-64.

2. Sharma $P$, Allison JP. The future of immune checkpoint therapy. Science. 2015;348(6230):56-61.

3. Tumeh PC, Harview CL, Yearley JH, Shintaku IP, Taylor EJ, Robert L, et al. PD-1 blockade induces responses by inhibiting adaptive immune resistance. Nature. 2014:515(7528):568-71.

4. Li K, Qu S, Chen X, Wu Q, Shi M. Promising targets for Cancer immunotherapy: TLRs, RLRs, and STING-mediated innate immune pathways. Int J Mol Sci. 2017;18(2):404.

5. Pasare C, Medzhitov R. Toll-like receptors: linking innate and adaptive immunity. Microbes Infect. 2004;6(15):1382-7.

6. Peng G, Guo Z, Kiniwa Y, Voo KS, Peng W, Fu T, et al. Toll-like receptor 8-mediated reversal of CD4+ regulatory $T$ cell function. Science. 2005: 309(5739):1380-4.

7. Tomai MA, Imbertson LM, Stanczak TL, Tygrett LT, Waldschmidt TJ. The immune response modifiers imiquimod and R-848 are potent activators of B lymphocytes. Cell Immunol. 2000;203(1):55-65.

8. Vasilakos JP, Smith RM, Gibson SJ, Lindh JM, Pederson LK, Reiter MJ, et al. Adjuvant activities of immune response modifier R-848: comparison with CpG ODN. Cell Immunol. 2000;204(1):64-74.

9. Wagner TL, Ahonen CL, Couture AM, Gibson SJ, Miller RL, Smith RM, et al. Modulation of $\mathrm{TH} 1$ and $\mathrm{TH} 2$ cytokine production with the immune response modifiers, R-848 and imiquimod. Cell Immunol. 1999:191(1):10-9.

10. Dudek AZ, Yunis C, Harrison LI, Kumar S, Hawkinson R, Cooley S, et al. First in human phase I trial of 852A, a novel systemic toll-like receptor 7 agonist, to activate innate immune responses in patients with advanced cancer. Clin Cancer Res. 2007;13(23):7119-25.

11. Link BK, Ballas ZK, Weisdorf D, Wooldridge JE, Bossler AD, Shannon M, et al. Oligodeoxynucleotide CpG 7909 delivered as intravenous infusion demonstrates immunologic modulation in patients with previously treated non-Hodgkin lymphoma. J Immunother. 2006;29(5):558-68.

12. Rook AH, Gelfand JM, Wysocka M, Troxel AB, Benoit B, Surber C, et al. Topical resiquimod can induce disease regression and enhance $T$-cell effector functions in cutaneous T-cell lymphoma. Blood. 2015:126(12):1452-61.

13. Tomai MA, Gibson SJ, Imbertson LM, Miller RL, Myhre PE, Reiter MJ, et al. Immunomodulating and antiviral activities of the imidazoquinoline S-28463. Antiviral Res. 1995;28(3):253-64.

14. Tomai MA, Vasilakos JP. TLR-7 and -8 agonists as vaccine adjuvants. Expert Rev Vaccines. 2011;10(4):405-7.

15. Miller RL, Meng TC, Tomai MA. The antiviral activity of toll-like receptor 7 and 7/8 agonists. Drug News Perspect. 2008;21(2):69-87.

16. Szeimies RM, Bichel J, Ortonne JP, Stockfleth E, Lee J, Meng TC. A phase II dose-ranging study of topical resiquimod to treat actinic keratosis. $\mathrm{Br} J$ Dermatol. 2008;159(1):205-10.

17. Harrington KJ, Puzanov I, Hecht JR, Hodi FS, Szabo Z, Murugappan S, et al Clinical development of talimogene laherparepvec (T-VEC): a modified herpes simplex virus type-1-derived oncolytic immunotherapy. Expert Rev Anticancer Ther. 2015;15(12):1389-403.

18. Rehman H, Silk AW, Kane MP, Kaufman HL. Into the clinic: Talimogene laherparepvec (T-VEC), a first-in-class intratumoral oncolytic viral therapy. J Immunother Cancer. 2016:4:53.

19. Gadkaree SK, Fu J, Sen R, Korrer MJ, Allen C, Kim YJ. Induction of tumor regression by intratumoral STING agonists combined with anti-programmed death-L1 blocking antibody in a preclinical squamous cell carcinoma model. Head Neck. 2017;39(6):1086-94.

20. Kadowaki N, Ho S, Antonenko S, Malefyt RW, Kastelein RA, Bazan F, et al. Subsets of human dendritic cell precursors express different toll-like receptors and respond to different microbial antigens. J Exp Med. 2001; 194(6):863-9.

21. Pockros PJ, Guyader D, Patton H, Tong MJ, Wright T, McHutchison JG, et al. Oral resiquimod in chronic HCV infection: safety and efficacy in 2 placebo-controlled, double-blind phase lla studies. J Hepatol. 2007:47(2):174-82

22. Smirnov D, Schmidt JJ, Capecchi JT, Wightman PD. Vaccine adjuvant activity of 3M-052: an imidazoquinoline designed for local activity without systemic cytokine induction. Vaccine. 2011;29(33):5434-42. 
23. Singh M, Khong H, Dai Z, Huang XF, Wargo JA, Cooper ZA, et al. Effective innate and adaptive antimelanoma immunity through localized TLR7/8 activation. J Immunol. 2014;193(9):4722-31.

24. Zhao BG, Vasilakos JP, Tross D, Smirnov D, Klinman DM. Combination therapy targeting toll like receptors 7,8 and 9 eliminates large established tumors. J Immunother Cancer. 2014:2:12.

25. Mosely SI, Prime JE, Sainson RC, Koopmann JO, Wang DY, Greenawalt DM, et al. Rational selection of syngeneic preclinical tumor models for immunotherapeutic drug discovery. Cancer Immunol Res. 2017;5(1):29-41.

26. Leyland R, Watkins A, Mulgrew KA, Holoweckyj N, Bamber L, Tigue NJ, et al. A novel murine GITR ligand fusion protein induces antitumor activity as a monotherapy that is further enhanced in combination with an OX40 agonist. Clin Cancer Res. 2017;23(13):3416-27.

27. Fakhari A, Nugent S, Elvecrog J, Vasilakos J, Corcoran M, Tilahun A, et al. Thermosensitive gel-based formulation for Intratumoral delivery of toll-like receptor 7/8 dual agonist, MED19197. J Pharm Sci. 2017;106(8):2037-45.

28. Gorden KB, Gorski KS, Gibson SJ, Kedl RM, Kieper WC, Qiu X, et al. Synthetic TLR agonists reveal functional differences between human TLR7 and TLR8. J Immunol. 2005;174(3):1259-68.

29. Edwards S, Jones C, Leishman AJ, Young BW, Matsui H, Tomizawa H, et al. TLR7 stimulation of APCs results in inhibition of IL-5 through type I IFN and notch signaling pathways in human peripheral blood mononuclear cells. J Immunol. 2013;190(6):2585-92.

30. Wang S, Campos J, Gallotta M, Gong M, Crain C, Naik E, et al. Intratumoral injection of a CpG oligonucleotide reverts resistance to PD-1 blockade by expanding multifunctional CD8+ T cells. Proc Natl Acad Sci U S A. 2016;113(46):E7240-E9.

31. Hornung $V$, Rothenfusser $S$, Britsch $S$, Krug A, Jahrsdorfer B, Giese T, et al. Quantitative expression of toll-like receptor 1-10 mRNA in cellular subsets of human peripheral blood mononuclear cells and sensitivity to CpG oligodeoxynucleotides. J Immunol. 2002;168(9):4531-7.

32. Goldinger SM, Dummer R, Baumgaertner P, Mihic-Probst D, Schwarz K, Hammann-Haenni A, et al. Nano-particle vaccination combined with TLR-7 and -9 ligands triggers memory and effector CD8(+) T-cell responses in melanoma patients. Eur J Immunol. 2012;42(11):3049-61.

33. Dummer R, Hauschild A, Becker JC, Grob JJ, Schadendorf D, Tebbs V, et al. An exploratory study of systemic administration of the toll-like receptor-7 agonist $852 \mathrm{~A}$ in patients with refractory metastatic melanoma. Clin Cancer Res. 2008;14(3):856-64

34. Chi H, Li C, Zhao FS, Zhang L, Ng TB, Jin G, et al. Anti-tumor activity of tolllike receptor 7 agonists. Front Pharmacol. 2017;8:304.

35. Brody JD, Ai WZ, Czerwinski DK, Torchia JA, Levy M, Advani RH, et al. In situ vaccination with a TLR9 agonist induces systemic lymphoma regression: a phase I/II study. J Clin Oncol. 2010;28(28):4324-32.

36. Adams S, Novik Y, Oratz R, Axelrod D, Speyer J, Tiersten A, et al. Clinical trial evidence of the antitumor activity of topical imiquimod for breast cancer skin metastases. J Clin Oncol. 2014;32(28):3204-5

37. de la Torre AN, Contractor S, Castaneda I, Cathcart CS, Razdan D, Klyde D, et al. A phase I trial using local regional treatment, nonlethal irradiation, intratumoral and systemic polyinosinic-polycytidylic acid polylysine carboxymethylcellulose to treat liver cancer: in search of the abscopal effect. J Hepatocell Carcinoma. 2017:4:111-21.

38. Salazar AM, Erlich RB, Mark A, Bhardwaj N, Herberman RB. Therapeutic in situ autovaccination against solid cancers with intratumoral poly-ICLC: case report, hypothesis, and clinical trial. Cancer Immunol Res. 2014;2(8):720-4.

39. Barnetson RS, Satchell A, Zhuang L, Slade HB, Halliday GM. Imiquimod induced regression of clinically diagnosed superficial basal cell carcinoma is associated with early infiltration by CD4 T cells and dendritic cells. Clin Exp Dermatol. 2004;29(6):639-43.

40. Sagiv-Barfi I, Czerwinski DK, Levy S, Alam IS, Mayer AT, Gambhir SS, et al. Eradication of spontaneous malignancy by local immunotherapy. Sci Transl Med. 2018;10(426):eaan4488.

41. Fox CB, Orr MT, Van Hoeven N, Parker SC, Mikasa TJ, Phan T, et al. Adsorption of a synthetic TLR7/8 ligand to aluminum oxyhydroxide for enhanced vaccine adjuvant activity: a formulation approach. J Control Release. 2016;244(Pt A):98-107.

42. Dowling DJ, van Haren SD, Scheid A, Bergelson I, Kim D, Mancuso CJ, et al. TLR7/8 adjuvant overcomes newborn hyporesponsiveness to pneumococcal conjugate vaccine at birth. JCl Insight. 2017;2(6):e91020.

43. Van Hoeven N, Fox CB, Granger B, Evers T, Joshi SW, Nana Gl, et al. A formulated TLR7/8 agonist is a flexible, highly potent and effective adjuvant for pandemic influenza vaccines. Sci Rep. 2017;7:46426.
44. Dovedi SJ, Adlard AL, Ota Y, Murata M, Sugaru E, Koga-Yamakawa E, et al. Intravenous administration of the selective toll-like receptor 7 agonist DSR-29133 leads to anti-tumor efficacy in murine solid tumor models which can be potentiated by combination with fractionated radiotherapy. Oncotarget. 2016;7(13):17035-46.

45. Dumitru CD, Antonysamy MA, Tomai MA, Lipson KE. Potentiation of the anti-tumor effects of imidazoquinoline immune response modifiers by cyclophosphamide. Cancer Biol Ther. 2010;10(2):155-65.

\section{Publisher's Note}

Springer Nature remains neutral with regard to jurisdictional claims in published maps and institutional affiliations.

Ready to submit your research? Choose BMC and benefit from:

- fast, convenient online submission

- thorough peer review by experienced researchers in your field

- rapid publication on acceptance

- support for research data, including large and complex data types

- gold Open Access which fosters wider collaboration and increased citations

- maximum visibility for your research: over $100 \mathrm{M}$ website views per year

At BMC, research is always in progress.

Learn more biomedcentral.com/submissions 